\title{
How does fishing alter marine populations and ecosystems sensitivity to climate?
}

\author{
Benjamin Planque ${ }^{a, ~}{ }^{\star}$, Jean-Marc Fromentin ${ }^{b}$, Philippe Cury ${ }^{b}$, Kenneth F. Drinkwater ${ }^{c}$, Simon \\ Jennings $^{\mathrm{d}, \mathrm{g}}$, R. Ian Perry ${ }^{\mathrm{e}}$ and Souad Kifani ${ }^{f}$
}

\footnotetext{
${ }^{a}$ Département Ecologie et Modèles pour l'Halieutique, Ifremer, rue de l'île d'Yeu, 44311 Nantes Cedex 3, France

${ }^{b}$ IRD, UMR EME 212 Centre de Recherche Halieutique Méditerranéenne et Tropicale, Avenue Jean Monnet, BP 171, 34203 Sète Cedex, France

${ }^{c}$ Institute of Marine Research and the Bjerknes Center for Climate Research, Box 1870, Nordnes, N-5817 Bergen, Norway

d Centre for Environment, Fisheries and Aquaculture Science, Lowestoft Laboratory, Lowestoft, NR33 OHT, United Kingdom

e Pacific Biological Station, Marine Ecosystems and Aquaculture Division, Fisheries and Oceans Canada, 3190 Hammond Bay Road, Nanaimo, Canada B.C. V9T 6N7

${ }^{\mathrm{f}}$ Institut National de Recherche Halieutique, 2, rue Tiznit, Casablanca, Morocco

${ }^{g}$ School of Environmental Sciences, University of East Anglia, Norwich, NR4 7TJ, United Kingdom
}

*: Corresponding author : Benjamin Planque, Present address: Institute of Marine Research Tromsø, Postboks 6404, 9294 Tromsø, Norway. Tel.: +47 776097 21, email address : benjamin.planque@imr.no

\begin{abstract}
:
Evidence has accumulated that climate variability influences the state and functioning of marine ecosystems. At the same time increasing pressure from exploitation and other human activities has been shown to impact exploited and non-exploited species and potentially modify ecosystem structure. There has been a tendency among marine scientists to pose the question as a dichotomy, i.e., whether (1) "natural" climate variability or (2) fishery exploitation bears the primary responsibility for population declines in fish populations and the associated ecosystem changes. However, effects of both climate and exploitation are probably substantially involved in most cases. More importantly, climate and exploitation interact in their effects, such that climate may cause failure in a fishery management scheme but that fishery exploitation may also disrupt the ability of a resource population to withstand, or adjust to, climate changes. Here, we review how exploitation, by altering the structure of populations and ecosystems, can modify their ability to respond to climate. The demographic effects of fishing (removal of large-old individuals) can have substantial consequences on the capacity of populations to buffer climate variability through various pathways (direct demographic effects, effects on migration, parental effects). In a similar way, selection of population sub-units within metapopulations may also lead to a reduction in the capacity of populations to withstand climate variability and change. At the ecosystem level, reduced complexity by elimination of species, such as might occur by fishing, may be destabilizing and could lead to reduced resilience to perturbations. Differential exploitation of marine resources could also promote increased turnover rates in marine ecosystems, which would exacerbate the effects of environmental changes. Overall (and despite the specificities of local situations) reduction in marine diversity at the individual, population and ecosystem levels will likely lead to a reduction in the resilience and an increase in the response of populations and ecosystems to future climate variability and change. Future management schemes will have to consider the structure and functioning of populations and ecosystems in a wider sense in order to maximise the ability of marine fauna to adapt to future climates.
\end{abstract}

Keywords: Climate-fishing interactions; Demography; Marine ecosystems; Resilience 


\section{Can the effects of climate and exploitation be separated?}

The effects of climate and exploitation on fish populations are widely perceived as additive only. Based on this perception, exploitation would act primarily as a removal function reducing the mean biomass of exploited populations. Climate fluctuations are often

5 considered as statistical noise that mostly contributes to the variance in population size. Under this simple representation in which climate and exploitation effects are considered to be additive (i.e. not interacting), increased exploitation is assumed to reduce mean abundance without changing the variance ${ }^{2}$. As the population decreases towards low values, the probability of a population collapse due to climate driven variability is thus supposed to increase. This simple model already calls for the control of exploitation in such way that a minimum level of abundance is maintained, and this minimum level is set by the amplitude of climate driven variability. Two important implications of an additive vision of climateexploitation interactions are that (1) it should be possible to separate climatic and exploitation effects and (2) populations that have recovered to substantial biomass levels should respond to climate variability in a similar way as they did in the past.

The idea that climate and fisheries impacts can be separated is still common. For example, Schiermeier (2004, p4) reporting on a Royal Society meeting held in London in 2004 stated: "to develop a sustainable fisheries policy, it will be crucial to determine how much of changing mortality patterns is due to fishing operations, and how much to environmental trends". More recently, Hsieh et al. (2006, p859) have also argued that "the separation of the effects of environmental variability from the impact of fishing ... is essential for sound fisheries management". What is less often considered is that fishing, and more importantly overfishing, can lead to changes in the way an exploited population responds to environmental fluctuations and to climate in particular. If for example, as suggested by Worm and Myers (2004), overfishing leads to increased sensitivity of fish populations to climate fluctuations, can the effects of fishing and those of climate really be separated?

\footnotetext{
${ }^{2}$ The authors do not share this point of view. However, it is reported here since it is a common view in climatefisheries studies (see for example Fig 3 in Pauly et al., 2002). Note that it can be argued that reduction in abundance naturally leads to decrease in variance, simply because natural populations follow log-normal distributions by which the variance is proportional to the mean. But it can be equally argued that recruitment variance can increase when abundance is reduced, as in Brander (2005).
} 
Theoretical work on population dynamics has revealed that the responses of populations to environmental effects do vary as a function of population characteristics (e.g. life history traits, density dependence, spatial structure), while empirical observations have demonstrated that fishing affects these characteristics (Halley 1996, Petchey et al. 1997, Begg et al. 1999, Lundberg et al. 2000, Olsen et al. 2004). Recently, an increase in population response to environmental signals has been demonstrated for one of the most studied fish populations, the North-east Arctic cod (Gadus morhua), and suggests that amplification of a fish population response to climate, possibly as a result of exploitation, is already at play in the ocean (Ottersen et al., 2006).

If, as it is argued here, exploitation can affect the way populations respond to climatic forcing, it is likely that recovery to a given population abundance or biomass will not be sufficient to also restore the patterns of population responses to climate. This will require that population characteristics other than biomass (e.g. demographic and spatial structures) also be restored. The other implication is that statistical climate-population relationships may display recurrent appearance / disappearance sequences, as has already been observed for a number of populations (see e.g. Myers, 1998).

If fishing can alter the structure of marine populations and consequently alter the nature of their responses to climate, the same will apply at the ecosystem level. For example, the replacement through overfishing of long-lived species by short-lived species with faster lifehistories would lead to changes in ecosystem response to climate fluctuations. Similarly, it may be expected that the removal of top predators by fishing could also modulate climate effects on top-down controlled ecosystem. Recent studies even postulated that fishing induced decline in biodiversity could reduce ecosystem resilience and lead to increased sensitivity to climate (see e.g., Worm et al., 2006, Tittensor et al., in press). However, such cascade effects often remain relatively simplistic (i.e., linear) and will require support from field studies and observation to be confirmed (see e.g. Frank et al., 2006).

It is not the aim of the present contribution to discuss the effects of fishing or climate on their own (this has been done in many reviews). The objective here is to analyse the way exploitation can alter the response of exploited marine populations and ecosystems to climate. In the following sections, we provide examples of mechanisms by which the effects of exploitation can interact with the way marine populations and ecosystems respond to climate. 


\section{Combined effects of climate and exploitation on fish populations}

\section{Modulation of climate signals by populations}

Interactions between exploitation and climate effects may be complicated by the fact that individuals and populations modulate the environmental noise and, most often, act as low-

5 pass filters. Secular time series on the Skagerrak cod clearly displayed long-term fluctuations that did not appear to be directly environmentally-driven (Fromentin et al., 1998), but probably resulted from stochastic variations in recruitment being echoed ${ }^{3}$ in the life cycle by inter-cohort interactions (Bjørnstad et al., 1999). The combination of interactions between age-classes, due to cannibalism or competition, and stochastic recruitment induced lowfrequency variability in population abundance. Using a simple age-structured model for bluefin tuna (Thunnus thynnus), Fromentin and Fonteneau (2001) also depicted long-term variations emerging from the combination of stochastic variations in recruitment and specific life history traits, especially longevity and the number of reproductive age-classes. Bjørnstad et al. (2004) gave an analytic framework to such a process, that they named "cohort resonant

15 effects", and showed how such innate low-frequency fluctuations could potentially mimic critical variations in abundance due to environmental changes or (over-)exploitation. These examples show that low frequency variations in populations can arise from short-term fluctuations and that population structure plays a critical role in the way external controls (whether human or climatic) reverberate in fish populations.

20 Additional work on population dynamics modelling has revealed that environmental forcing is more visible in semelparous populations (in which individuals reproduce once in their lifetime), than in iteroparous populations (in which individuals reproduce several times, Kaitala and Ranta, 2001). As exploitation leads to the truncation of age structure towards younger age groups, the reproductive mode of an iteroparous population tends to become closer to semelparity (i.e. individual fish have less and less opportunity to reproduce over several years) and thus to be more visible. These simple patterns may become more complex when individual age, growth, maturity and fecundity are considered (see the section below on recruitment).

\footnotetext{
${ }^{3}$ The term "echo" is used as a synonym of the term "resonate", i.e., a process leading to the prolongation and/or the alteration of the properties (intensity and frequency) of a noise.
} 


\section{Climate impact on fishing practices}

While examples of climate impacts on fish populations are well documented (e.g. Ottersen et al., this volume, Schwing et al., this volume), the effects of climate fluctuations can also be seen in the response of fishing practices. Such effects have been described in the case of the Northern cod fisheries off southern Labrador and northeast Newfoundland. The persistent cold ocean temperatures in the region occupied by Northern cod that occurred through most of the 1980s and early 1990s led to slow growth and cod in poor condition, attested to by the fisherman who called them "skinny cod" (Drinkwater, 2002). This poor condition is thought to be a result of changes in available preys associated with the lower temperatures. Other fish species, including American plaice (Brodie, 1987), and capelin (Nakashima, 1996) also experienced similar slow growth, which was thought to be linked to the declines in temperature. The poor condition of the cod had two significant consequences. The first was that the fish had less energy resources available to put into reproduction; they were simply struggling to stay alive. The second important effect was a direct interaction between an environmental effect and fishing. Fishermen are known to have dumped some of these poor conditioned fish overboard while at sea in favour of keeping larger fish, which fetched a better price. This illegal activity, known as "high-grading", was acknowledged by many fishermen and documented by Kulka (1997). High-grading continued through to 1992 when a moratorium on fishing cod was imposed with an average of 4-5 million cod being dumped each year during the late 1980s and early 1990s. The average age of the dumped fish declined during this time from $4-5$ years in the mid-1980s to $2-3$ by the time the moratorium was imposed. Therefore many of these fish were either sexually immature or first-time spawners. These estimates are thought to be on the low side as greater high-grading is likely to have occurred when observers were not on the ship or when not on deck. Thus, in this case, the combination of direct climate effects on fish (causing slow growth, poor condition) with the indirect consequences on fishing practices (high-grading) associated with truncated age structure resulted in additional stress on an already stressed stock, thereby contributing to the collapse of Northern cod (Drinkwater, 2002). General effects of fishing on age structure are detailed in the following section.

\section{Alteration of demographic structure}

"Fishing is almost always non random. Typically, gear is designed to remove some kind of individuals in preference to others, usually individuals that are larger and, indirectly, older" 
(Law, 2000, p. 659). Size selective fishing results in a general decrease of the proportion of large individuals within populations and a reduction in the relative abundance of large species within communities. Fishing induced changes in body size and body size distributions are such general responses to fishing that they have been proposed as size based indicators (SBIs) which could be used to evaluate the impact of fishing on marine populations and communities (Shin et al., 2005). At the global scale size-differential fishing has resulted in a sharp decline in the mean maximum length of fish landed during the last century (Fig 1). At the population level the direct consequence of fishing is a reduction in population size, which is largely due to the truncation of age structures and the reduced contribution of larger and older individuals to total abundance. Many examples of such demographic truncation have been described for cod stocks: Northern Canadian cod (Longhurst, 1998), Icelandic cod (Marteinsdottir and Thorarinsson, 1998), Barents Sea cod (Ottersen et al., 2006) and North Sea cod (ICES, 2006). Recently Marteinsdottir et al. (2005) reported a decrease in older fish and age diversity of mature fish in 12 out of 16 cod stocks around the North Atlantic. In the North Atlantic the maximum length attained by species landed from 1950 to 2000 decreased from $95 \mathrm{~cm}$ to around $65 \mathrm{~cm}$. At a global level there has been a 25\% reduction in the mean maximum length of landed fish from coastal areas (Trites et al., 2006).

What are the consequences of a truncated demographic structure on a population subjected to climate variability? Theoretical population dynamics studies and empirical observations of populations with different age structures provide some answers on the potential consequences of fishing-induced changes in population demographic structure.

\section{Buffering capacity}

An important feature of climatic/environmental signals is that they tend not to resemble white noise but in many cases are reddened, i.e. variance is higher at lower frequencies (Steele, 1985; Halley, 1996; Vasseur and Yodzis, 2004). One consequence is that successive years of good or bad conditions happen more frequently. This led Lawton (1988) to postulate that reddened noise increases the risk of population extinction due to a higher probability of consecutive years of adverse conditions. One implication for populations is that they need to have the ability to cope with runs of bad conditions while waiting for better ones to occur. Longevity, iteroparity and overlapping generations can be interpreted as adaptations to cope with such variability (Murphy, 1967, 1968; Longhurst, 2002; Secor, 2007). A fish population with many year classes can indeed survive during long periods of adverse environment (and low recruitment) until favourable conditions (which can produce a high year-class) occur, 
whilst a fish population with only a few cohorts may collapse before the return of favourable conditions (Fromentin and Fonteneau, 2001). The high number of year-classes (or age groups) therefore provides a "buffering capacity" for the population (also termed "storage effect" by Chesson and Warner, 1981) and can constitute the "insurance policy" of the population (Field and Francis, 2002). The idea is supported by empirical evidence that fish species with higher recruitment variability generally display greater longevity than species with lower recruitment variability (Longhurst, 2002). Consequently, the biomass of short lived species is more variable than this of long lived species under reddened environmental noise, as indicated by the well documented long-term cycles of anchovy and sardine in several coastal upwelling areas (Schwartzlose et al., 1999).

These observations lead us to conclude that under similar climate forcing, populations of long-lived species with fisheries induced truncated age structures will be more prone to collapse (and the collapse will likely be attributed to environmental causes). The critical situation of the North Sea cod is a good example of this phenomenon. On the one hand, the long-lasting heavy exploitation has strongly depleted the spawning stock biomass that now only consists of only a few age-classes of young adults (ICES, 2006). On the other hand, the recruitment success of this stock is negatively related to temperature (Planque and Frédou, 1999; O'Brien et al., 2000), so that two decades of warmer conditions (i.e., red environmental noise) increased recruitment failures and thus reinforced the depletion of the stock and extinction risk. This is further amplified if the effect of temperature on recruitment is greater when stock biomass is low, as suggested by Brander (2005). Another example is given by the northern cod. In the early 1960s, their age-structure contained 18 year-classes (if groups representing less than 5000 tons are excluded) but by the mid-1990s the older fish had disappeared and the age structure was reduced to 9 year-classes (Drinkwater, 2002), therefore reducing the capacity of the population to resist several successive years of poor environmental conditions.

Aside from the indirect effects of climate variations (e.g. on fishing), the effect of long term changes in the environment on fish populations can be more complex than those originally described by Lawton (1988). Whilst Lawton postulated that reddened noise increases population extinction due to a higher probability of consecutive years of adverse conditions, recent theoretical work has shown that the risk of extinction of a population does not solely and directly depend on the colour of the environmental noise, but on its interactions with biological processes (Halley, 1996; Morales, 1999; Petchey et al., 1997; Ripa and Lundberg, 
1996). In theory, environmental red noise is more likely to decrease persistence of populations with undercompensatory ${ }^{4}$ dynamics but would increase that of populations with overcompensatory ones (and inversely for white noise, Petchey et al., 1997). Climate change is likely to redden environmental noise while exploitation can relax regulation processes (e.g. density dependence) in fish populations. Both mechanisms can thus lead to changes in the way climate-driven environmental variability reverberates in fish population dynamics.

\section{Consequences on recruitment}

Aside from altering the response of adult populations to climate forcing, one possible consequence of changes in age structure may be an increased coupling between climate fluctuations and recruitment variations. In a recent study, Ottersen et al. (2006) argue that such changes have occurred for North-east Arctic cod. This cod stock has been monitored for several decades (Ottersen et al. have analysed data back to 1943) and sea temperature, which provides an integrative index of major physical control over the whole Barents Sea area, has been measured during the same period (Tereshchenko, 1996). The statistical relationship between temperature and the recruitment of Barents Sea cod has been known for some time (e.g. Ottersen et al., 1994), but the potential role of population structure had not been considered. Whilst the spawning stock biomass (SSB) of NE Arctic cod was dominated by $13+$ year old fish in the late 1940s and early 1950s, the population demographic structure shrank and SSB became dominated by 6-8 year old fish in the 1990s. During that period the correlation between sea temperature and recruitment persistently increased (Fig. 2).

This interesting case study relies on recent findings on fish reproduction, which are generally embraced under the term "parental effects" (see Birkeland and Dayton, 2005 for a recent review). Whilst the study of stochastic processes and environmental conditions have been central to recruitment studies during the last century (following Hjort, 1914; Hjort, 1926; Cushing, 1982), a series of recent studies has renewed the focus on the key role played by the age structure of the spawning population. Indeed, older and larger females are not only more fertile (the number of eggs per gram of body weight is generally rather constant), but also produce larger eggs, more viable larvae and spawn in a different temporal and spatial window

\footnotetext{
${ }^{4}$ The terms over- and under-compensation are widely used in population dynamics (especially fisheries science) to depict the intensity of density-dependence in reproduction. Overcompensation occurs when the total number of recruits decreases at large spawning stocks (see e.g. the Ricker model). In contrast, undercompensation occurs when the number of recruits at large spawning stocks is higher than expected under exact compensation.
} 
(Marteinsdottir and Thorarinsson, 1998; Cardinale and Arrhenius, 2000; Berkeley et al. 2004a). This means that the population reproductive potential is greater if larger/older individuals are proportionally more abundant, and also that their post-hatch larvae can sustain longer periods of starvation, making them less vulnerable to "mismatch" situations as described in Cushing's match-mismatch hypothesis (Cushing, 1990). Furthermore, larger/older females display a longer spawning period than smaller/younger fish (Secor, 2007 and references therein) and generally spawn over a larger area (both in the horizontal and vertical dimensions), with repeat spawners producing eggs that have a wider range of vertical distribution than recruit spawners thus causing broader horizontal dispersion, (see e.g. Kjesbu et al., 1992; Kjesbu et al., 1996; Berkeley et al., 2004b). Altogether, the presence of old individuals in the spawning stock increases the viability of the eggs and larvae, which are thus expected to experience a wider range of environmental and trophic conditions, leading to potentially higher chances of survival and recruitment success under similar environmental variability. This is not only true for the North-east Arctic cod (Marshall et al., 1998; Makhotin et al., 2001) but has been observed for other cod stocks around the North Atlantic (Dutil et al., 1998; Marteinsdottir and Thorarinsson, 1998; Vallin and Nissling, 2000) as well as rockfish species (Berkeley et al. 2004a). In contrast, the spatial and temporal contraction of spawning, which can result from truncation of the age structure, would increase the dependence of egg and larval survival on restricted set of environmental conditions, therefore tightening the link between recruitment and the environment. Such a mechanism is consistent with observations on several cod stocks, which indicate that environment-recruitment relationships are tighter when stock biomass is low (Brander, 2005).

\section{Consequences on migration}

In most animal populations, many individuals use information provided by others to make decisions related to feeding, mating or migrating. Brown and Laland (2003) show that fish populations are not exceptions and that social learning can play a critical role in transferring information from knowledgeable individuals to newcomers (also called "observers" in the social learning literature, Heyes and Galef, 1996). The importance of social learning for spawning migrations has been demonstrated experimentally for several coral reef species (Warner, 1988) and is generally accepted for fish species that can repeat experiences (i.e. iteroparous reproduction), while semelparous fish species, such as salmon, would mostly display strict fidelity to the birth location due to imprinting of environmental cues during their early life stages (Dodson 1988). Experimental evidence is lacking for fish undergoing large- 
scale migration but empirical observations support similar findings for herring (Clupea harengus) in the North Sea (Corten, 2002). The idea developed by Corten (2002) under the terminology of "conservatism in migration” can be summarised by two main principles. First, fish that have spawned in a given location tend to return to the same location in successive years (habit formation) and second, old-knowledgeable fish transmit their migration knowledge to young-newcomer fish (tradition). The combination of habit formation and tradition leads herring populations to adopt spawning migration patterns which tend to be maintained over multiple years (despite changing environmental conditions). Once lost (due to overfishing or other factors), these patterns may not always be restored. This is described by Corten (2002, p. 342): "In the 1950s and 1960s the stock used to spawn at a large number of separate spawning sites throughout the western and southern North Sea. The number of these spawning sites, however, was sharply reduced in the 1970s, when the North Sea stock was reduced by overfishing to less than $2 \%$ of its original level [...]. When the stock in the 1980s recovered as a result of conservation measures, the herring did not re-occupy most of the spawning sites that had earlier been deserted."

One potential consequence of truncating the age structure is that the removal of older individuals can lead to a loss in tradition. For example, there may not be enough old individuals to lead young ones to spawning/feeding/wintering grounds. Since long-range migration capabilities also depend on energy storage at the individual level (Slotte and Fiksen, 2000), another possible consequence of removing old/large individuals is an overall reduction in population migration range due to reduction in mean energy storage levels. This hypothesis is consistent with empirical observations of the Norwegian spring spawning herring population. Migration range contracted during the 1970s when the population declined and fish condition was poor but re-expanded further south in the 1980s during years when fish conditions improved. Additional observations suggest that there is a tendency for a year class to spawn farther south as it gets older (Slotte, 1999; Slotte and Fiksen, 2000). The importance of older individuals in maintaining population life-cycle closure through migration patterns has recently been re-emphasised by Petitgas et al. (2006).

As seen in the herring examples, conservatism in migration confers a buffering capacity against climate driven variations in the environment. Truncation in age structure, by altering 
migration patterns and persistence, may therefore lead to greater sensitivity to climate fluctuations ${ }^{5}$.

In conclusion, the demographic effects of fishing have a number of consequences which include reduction in buffering capacity, possible increase in recruitment variability, and lack of resilience in migration patterns; all of which are likely to increase sensitivity to climate forcing. The truncation of age-structure as a result of fishing practices has recently been termed "longevity overfishing" and calls for management objectives to include the maintenance of age structure as well as biomass (Beamish et al., 2006).

\section{Alteration of populations with multiple sub-units}

Fishing is spatially organised as fishermen, far from randomly sampling the ocean, target specific fishing grounds. Thus habitat degradation, due to fishing or other activities, is also patchy and may affect some fishing grounds more than others. Fisheries management is concerned with fish stocks which form spatially bounded management units, but the spatial definition of fish stocks and the true spatial extent of fish populations do not necessarily match. Furthermore, the concept of meta-populations, which is well developed in ecology, is often unknown or ignored in fisheries management. A meta-population can be defined as a system of discrete local populations, each of which determines its own dynamics to a large extent, but with a degree of demographic influence from other local populations through dispersal of individuals (Kritzer and Sale, 2004). The response to climate variability and change is likely to vary between individual population units so that any change in metapopulation structure can lead to changes in the whole population response to climate forcing. Examples of such responses can be found for a number of fish populations including diadromous, demersal, small and large pelagic species (Kritzer and Sale, 2006).

As an example, Eastern Scotian Shelf cod used to spawned both in the spring (April/May) and in the fall (November/December) (Brander and Hurley, 1992). In the mid-1980s, however, the

\footnotetext{
${ }^{5}$ Shima (2002) proposes another perspective by suggesting that the removal of knowledgeable individuals may free young fish from tradition and therefore enhance their capacity to sample the environment, "leading to populations more equipped to track optima in changing climatic regimes”. However, without guidance from knowledgeable adults this may also lead to a significant loss in population productivity as a result of many fish spawning and migrating to the "wrong” places. This could further amplify the effect of the environment on fish populations.
} 
fall spawning component disappeared at a time when the cod abundance was rapidly declining and the fishing mortality was relative high (Frank et al., 1994). They have never returned. It was believed that this was due to the fall component being fished out, although the possibility of the cod having switched to spring spawning only could not be ruled out (Frank et al., 1994). At the same time, the previous strong inverse correlation between Eastern Scotian Shelf cod recruitment and the discharge from the St. Lawrence River failed (Frank et al., 1994). The possibility that this change in the recruitment-environment relationship resulted from other environmental changes can not be excluded, but it is likely that the relationship reversed because of changes in the seasonal components of the population.

\section{Buffering capacity}

The case of Bristol Bay (Alaska) sockeye salmon (Oncorhynchus spp.) provides a good example of a species that forms several sub-populations that perform well in distinct environmental situations. The Bristol Bay population is composed of multiple units associated with particular river systems (Fig. 3a). Each system displays a particular physical environment and the life-history traits of sockeye salmon in each system has specific characteristics (Hilborn et al., 2003). Multidecadal variations in the climate of the North Pacific (as exemplified by the Pacific Decadal Oscillation index, Fig 3b) have resulted in regional environmental changes with distinct local consequences on each population subunit (Fig 3c). Subunits that provided a marginal contribution to the Bristol Bay salmon catches at the beginning of the $20^{\text {th }}$ century now represent a sizeable fraction of total catches. The apparent stability in the productivity of the Bristol Bay population has resulted from the ability of the population to respond to climate fluctuations in a variety of ways, each associated with distinct population subunits. In this example, the meta-population structure appears to have acted as a buffer against climate variability.

A second example is provided by the Bay of Biscay anchovy (Engraulis encrasicolus). In a detailed study of anchovy larvae Allain et al. (2003) have shown that transport might be a key mechanism driving larval growth and survival. Adult anchovy can spawn in different habitats and the fate of larvae depends upon the timing and location of egg release so that the relative contribution of various spawning grounds to the overall recruitment may vary from year-toyear (Allain, 2004). In such situations, changes in the spatial configurations (due to fishing or to environmental control) lead to changes in the response of the population to interannual variations in climatic conditions (as expressed in egg and larval drift). Long-term changes in the spatial distribution of anchovy have occurred, and from the beginning of the $20^{\text {th }}$ century 
to the 1980s, the spawning locations have contracted towards eastern waters of the Bay of Biscay (Junquera, 1986). It is still unclear whether this change resulted from environmental or fisheries controls but the displacement of the spawning habitat is likely to have resulted in a more unified response of anchovy recruitment to climate forcing, and may have contributed to the recent decline in the stock biomass.

These two contrasting examples suggest that maintenance of meta-population structure, through preservation of the sub-units, acts as a buffer against climate driven variations, whilst the removal of sub-units should lead to a weakening of the populations, making them more susceptible to climate. The processes by which differential response of population sub-units to climate and the dynamics of fishing practices interact have rarely been precisely described. However, this type of interaction may have dramatic effects on the resilience of populations and their ability to cope with climate (Fig. 4). It is important to note that such interactions between climate and fishing can only be understood if the system is considered from a dynamic rather than an equilibrium perspective.

\section{Consequences on migration}

The case of the Norwegian spring spawning herring illustrates how interactions between climate and fishing can alter migration patterns. The abundance of Norwegian spring spawning herring increased in the 1920s in parallel with an increase in ocean temperatures (Toresen and Østvedt, 2000). High temperatures are necessary but not sufficient to support high recruitment, i.e. at low temperatures recruitment is always low but at high temperatures recruitment can be high or low. The stock also underwent large distributional changes (Vilhjálmsson, 1997). During the warm period, herring migrated from their spawning locations on the west coast of Norway and around the Faroes, and from their nursery areas in the western Barents Sea, to the feeding grounds off north eastern Iceland. They migrated farther West during this warm period as confirmed by the first ever reports of herring at Jan Mayen in 1930-1931 (Cushing, 1982). The overwintering grounds at this time were primarily to the East of Iceland and then in spring, the herring migrated back to their spawning grounds (Fig. 5a).

When temperatures began to cool, the abundance of the herring stock decreased substantially, due not only to climate but also to increased fishing pressure resulting in the decline of the spawning stock biomass (SSB) in the 1960s (Toresen and Østvedt, 2000; Fiksen and Slotte, 2002). The commercial collapse of the Norwegian spring spawning herring led to a 
moratorium on fishing for herring. During the cold period, the Arctic Front in the Nordic Seas between the cold Arctic waters to the northwest and the warmer Atlantic waters to the southeast shifted south eastward and the herring feeding grounds moved farther eastward and then to southwest of Svalbard. When the population declined to drastically low levels, those individuals remaining no longer migrated out into the Norwegian and Greenland seas but stayed near the Norwegian coast to both feed and spawn (Vilhjálmsson, 1997, Fig. 5d).

In the 1990s, as temperatures warmed and after approximately 20 years of the imposed fishing ban, the herring population increased and they again began migrating large distances to feed (Vilhjálmsson, 1997). However, the new migration pattern developed with a spatial configuration different from that which prevailed during the 1950-70s (Fig. 5e, Dragesund et al., 1997; Vilhjálmsson, 1997). Although the exact roles played by fishing and climate are still unresolved, both were involved. It is not clear whether the reduced migration was due to the collapse of the population (due to fishing and climate) or if it was predominantly climate driven. However, the recent return of large-scale migration with a pattern distinct from the one observed in the 1950-70s suggests that bringing populations biomass back to pre-collapse levels may not be sufficient to bring migration patterns back to their historical configurations (see also previous section “Alteration of demographic structure”).

\section{Habitat loss, spatial shifts and ranges}

The abundance and distributional range of a population are linked and as abundance falls so the range of a population will contract (MacCall, 1990; Fisher and Frank, 2004). At low population abundance, populations tend to be restricted to habitats with the highest suitability (hotspots) while at high population abundance they also use habitats of lower suitability. Various models have been advanced to describe changes in distribution with abundance. A commonly applied model is based on the ideal free distribution (IFD) which describes how

25 individuals spread into less preferable habitats as the local density increases. According to the IFD model, individuals ultimately settle into the areas that allow them to achieve equal and maximum fitness (realised suitability) (Fretwell and Lucas, 1970). The consequence of distribution-abundance relationships is that heavily fished populations of reduced abundance tend to contract into smaller areas towards the centre of their possible range (Blanchard et al., 2005; Hutchings, 1996).

The reduction in the range of a population due to fishing will reduce the area in which competitive and predatory interactions occur and will allow scope for other populations that 
have been less impacted by fishing, and/or are moving in response to changes in temperature, to colonise parts of the original populations' former range. If such populations do invade, it may not be possible for the exploited species to recolonise even if fishing pressure is reduced. There do not appear to have been any studies of these processes, but it may be possible to ask, for example, whether the reduction in the biomass and range of cod in the North Sea allowed another predator that favours warmer waters, the bass (Dicentrarchus labrax), to colonise faster than would otherwise have been expected and whether any interactions have suppressed potential recovery of the cod.

Shifts in the spatial distribution of fish in response to environmental conditions are commonplace. Many examples were observed in the northern North Atlantic during the warming period of the early $20^{\text {th }}$ century and the subsequent cooling period around the $1960 \mathrm{~s}$ and 1970s (ICES, 1949; Beverton and Lee, 1965; Cushing and Dickson, 1976; Drinkwater, 2006). Associated with the warm period there was a general northward movement of fish. Boreal species of fish such as cod, haddock and herring expanded farther north while colder water species such as capelin and polar cod retreated northward. The maximum recorded movement involved cod, which spread approximately $1200 \mathrm{~km}$ northward along West Greenland. Migration patterns of "warmer water" species also changed with earlier arrivals and later departures. New spawning sites were observed farther North for several species or stocks while for others the relative contribution from northern spawning sites increased. Some southern species of fish that were unknown in northern areas prior to the warming event became occasional, and in some cases, frequent visitors (Perry et al., 2005). Distributional shifts were not restricted to fish species, for example there was a northward spread of benthos off Western Svalbard and eastward into the eastern Barents Sea associated with increased transport of Atlantic waters. As seen from these examples, the spatial extent and latitudinal range occupied by populations may be altered by fishing (via reductions in population size), by species interactions and by climate. However, little is known of the interactions between these control mechanisms and this area of research remains largely unexplored.

\section{Changes in life-history traits}

Fishing modifies life histories by reducing intraspecific competition and causing genetic selection. As fishing mortality is increased, these changes in life histories partially compensate for the lost reproductive value. Typically the changes include increases in growth rates and reductions in the age and size at maturity, leading to greater reproductive output 
earlier in life. While the effects of reduced intraspecific competition and genetic selection may only act directly on a single life history trait such as growth, compensatory adjustments in other life history traits will also occur that serve to maximise the lifetime reproductive success of the population.

5 Changes in life histories due to fishing often have a genetic component because fishing is selective with respect to heritable life-history traits such as growth. These changes are expected because the selection generated by fishing is strong (selection differentials) and the heritability of life history traits is high (Law and Rowell, 1993; Law, 2000). These effects have been demonstrated experimentally when populations of crustaceans are subjected to size-selective harvests (e.g. Law and Grey, 1989). There are several examples of trends in life history traits such as growth and age at maturity that have been attributed to phenotypic plasticity (Olsen et al., 2004) or the genetic effects of fishing (see e.g. de Roos et al., 2006), notwithstanding the ongoing debate about the validity of some of the methods that have been used to demonstrate them.

15 If heavily fished populations exhibit faster life histories, then how might this affect their response to climate change? It is already known that species do not redistribute at the same rate in response to climate variation and change and that some of the differences in rate can be attributed to differences in life history. Perry et al. (2005), for example, showed that species with small body size and therefore "fast" life histories have changed in distribution more rapidly following climate change than those with "slow" life histories, and Murawski (1993) suggested that smaller prey species were affected more rapidly than their predators. We therefore expect that fish populations which exhibit faster life histories as a consequence of fishing effects are likely to redistribute faster in response to environmental change. Coupled with the observation that fishing leads to greater instability in biomass and range, fishing can be seen as a driver that exacerbates the effects of climate change. There is considerable work to be done on the interplay between the effects of fishing on abundance, life histories and range size and the effects of these changes on a populations' response to climate variation and change. 


\section{Combined effects of climate and exploitation on marine ecosystems}

\section{Food web complexity and stability}

There remains debate about how similar marine food webs are to terrestrial and freshwater food webs, and the extent to which theory developed for terrestrial and freshwater systems applies to marine systems. Marine food webs tend to be more connected, have greater numbers of links per species, longer connecting chains, and greater proportions of intermediate, omnivorous, and cannibalistic taxa than most terrestrial and freshwater systems (Link, 2002; Dunne et al., 2004; Cury et al., 2005). This high degree of interaction, often mediated through weak links (Bascompte et al., 2005), provides marine food webs with greater resilience to external stresses. Link et al. (2006) suggest that due to their high degree of interactions, most marine food webs should display high resilience to perturbations and be robust to losses of species. However, removal of highly connected taxa (such as fish at middle or high trophic positions) can cause higher levels of secondary losses than random removal of taxa (Dunne et al., 2004). Fishing, which tends to target organisms at relatively high trophic levels more intensively, may provide strong pressure on these highly-connected species, and so the potential for significant community-wide effects remains even in marine systems. This suggestion is reinforced by recent studies which suggest (1) that biodiversity decline can lead to reduction in ecosystem production and resilience (Balvanera et al., 2006) and (2) that heterogeneity in food web channels (and in particular the presence of top level consumers which ultimately feed through various channels) provides ecosystems with a mechanism for responding to perturbation and ensures greater stability than in less heterogeneous ecosystems (Rooney et al., 2006).

Bascompte et al. (2005) provide an example of how over-fishing of sharks in the Caribbean may have contributed to the depletion of herbivorous fishes on coral reefs as a result of trophic cascades, thereby contributing to the shift from coral to algal-domination in these systems (cf. Hughes, 1994). Examples of how marine food webs have responded to both climate and fishing impacts can be found in the North Atlantic. The Barents Sea has experienced two (and possibly three) episodes during the past few decades in which the collapse of capelin (Mallotus villosus) has altered the food web including marine mammals and birds (Ciannelli et al., 2006). The Barents Sea represents a simplified food web (Fig. 6) with a few strongly connected species, among which are capelin, Atlantic cod, and Atlantic herring. Climate-forced increases in water temperature positively influence the population 
dynamics of cod and herring, which increases their predation on capelin; this effect is reinforced by fishing on capelin (Hjermann et al., 2004). However, the dominant species and food web dynamics of this system tend to recover several years after each collapse, suggesting the Barents Sea may shift between two states (Ciannelli et al., 2006).

5 The North Sea has experienced warming conditions for the past several decades, along with high fishing pressure. This has caused changes in species distributions (Perry et al., 2005) and changes in food webs. Heath (2005) describes how the functioning of the North Sea marine food web since the 1970s has been altered by the combination of fishing and climate effects. In particular, there have been increases in planktivorous pelagic fishes, reductions in piscivorous demersal fishes, and increased production of benthic macro-invertebrates. Heath (2005) concluded that, whereas individual pelagic fish species were affected by fishing, functionally-similar species expanded to fill the vacant niches. This suggested that the pelagic food web was controlled by bottom-up processes (primary production and oceanographic and climate-related processes). Demersal fishes, in contrast, were depleted by fishing but no other demersal fish species expanded to fill the vacant niches. As a result, the production of benthic macro-invertebrates increased. Heath (2005) concluded that the demersal food web was largely controlled by top-down processes, with major changes over this time period largely driven by fishing rather than variation in benthic secondary production. This suggests that pelagic feeding may be more "generic", allowing greater flexibility among pelagic species, whereas demersal feeding may be more specialised. Shurin et al. (2002), in a meta-analysis of marine predator effects, also concluded that evidence for trophic cascades was stronger in marine benthic and weaker in marine plankton studies. Heath (2005) further noted that climate processes do influence the recruitment of several North Sea demersal fish species, but concluded these were not sufficient to offset the impacts of fishing.

Food web models constructed for the periods before and after the collapse of cod in the Northwest Atlantic (specifically for the eastern Scotian Shelf) also demonstrate changes in the predator structure, trophic structure, and energy flow in this system (Bundy, 2005). The abundance of small pelagic fishes increased after the collapse, so that the system shifted from a demersal-feeder dominated system to a pelagic-feeder dominated system. As occurred in the

30 North Sea, the Scotian Shelf also experienced increased macro-benthos abundance and invertebrate fisheries (Frank et al., 2005). In a large meta-analysis, Hutchings and Baum (2005) also noted that declines of several northern hemisphere demersal fish populations have 
been associated with substantial increases in pelagic fish abundances, which is consistent with the hypothesis of reduced predation mortality on the pelagic species.

The tropical Pacific Ocean provides a contrasting system in which to compare climate, fishing, and food web effects. The food web in the tropical Pacific is diverse and complex, the environment has strong horizontal and vertical gradients (compartments), species which migrate between these compartments, and diverse fish, crustacean, and cephalopod taxa (Fig. 6). The region is strongly influenced by climate variability, in particular associated with ENSO (El Niño Southern Oscillation) events, and its top predators (tunas, billfishes, sharks) experience strong fishing pressure. Tuna recruitment and population fluctuations are controlled by physical (bottom-up) and “middle-down” (predation on larvae by epipelagic micronekton) processes, rather than via top-down effects from the highest trophic levels (Ciannelli et al., 2006). Ward and Myers (2005) hypothesised that intense industrial fishing since the 1950s reduced the abundances of the large predatory species which led to increased abundances of species at intermediate trophic levels, but the validity of this hypothesis is still debated. Watters et al. (2003), using a food web model of the eastern tropical Pacific, concluded that fishing might both mitigate and reinforce the effects of climate warming. Sustained reductions of fishing might mitigate negative effects of warming on the higher trophic levels, but would result in increased predation on their prey. Watters et al. (2003) also found that direct physical effects on predator recruitment dynamics could be a dominant source of variability in these pelagic ecosystems, such that they could dampen top-down control by fisheries. Watters et al. (2003, p. 1174) concluded "top-down effects of fishing are less able to cascade through the food web if direct effects [of climate on recruitment] are the dominant source of physical variability in the system."

\section{Accelerating life-histories}

25 Fish communities are composed of species with a range of life histories that interact through competition and predation and show different responses to fishing. Fishing leads to reductions in the relative abundance of species with slower life histories and relative, and sometimes absolute, proliferation of species with faster life histories (Jennings et al., 1999; Daan et al., 2005; Duplisea, 2005; Pope et al., 2006). The release from predation due to elimination of top predators can result in the proliferation of species that are at high trophic levels but have short life spans. This is the case for example in north and west-Africa (Morocco, Mauritania and Senegal) where octopus (Octopus vulgaris) became abundant after the overexploitation of 
demersal fish species, particularly sparidae (Gulland and Garcia, 1984). In Morocco and Mauritania the outburst started in the 1965s, and later on, in the 1980s, in Senegal. Those species represent now major resources for those countries but have been shown to fluctuate widely from one year to another as a result of variations in intensity of upwelling (Faure et al., 2000). Those ecosystem changes in a large marine ecosystem stress the fact that fishing can promote species having a fast turn-over rate (octopus have a life span of one year or less) but a high trophic level (between 3.2 and 4.2) resulting from the depletion of the major predatory demersal fish resources.

Differential exploitation of marine resources as well as ecosystem structural and dynamical responses to exploitation promotes ecosystems with increasing turn over rates, higher production to biomass ratio, lower overall rates of predation mortality and a dominance of smaller individuals and species (Duplisea and Kerr, 1995; Bianchi et al., 2000; Gislason 2002). In exploited communities, the effects of top-down predatory control on much of the community will be reduced, and bottom-up processes are expected to play a relatively more important role in driving community dynamics therefore leading to more pronounced effects of environmental changes. The greater sensitivity of overexploited communities to bottom-up processes suggests that climate variability will have a greater impact on the structure of these communities, leading to greater variation in biomass and production and more rapid changes in species composition. Small species in a community are likely to respond to climate change more rapidly than larger species (Perry et al., 2005) and this may influence prey availability for the larger species (e.g. Murawski, 1993).

\section{Mitigating impacts of fishing and climate - management responses}

\section{Keeping the big ones}

Size related fisheries regulations date back to the origins of fisheries management. These usually focussed on protecting small/young individuals in order to ensure that reproduction can take place before fish are captured by the fishery. Within ICES ${ }^{6}$ waters, regulation of landing size or mesh size have been recommended since the origins of ICES and date back to much earlier times in European national regulations. Minimal landing size and mesh size have been major management tools during the $20^{\text {th }}$ century and are still commonly used. This

\footnotetext{
${ }^{6}$ International Council for the Exploration of the Sea
} 
emphasis on preserving young individuals (to ensure reproduction and maximise the yield per recruit) may have obscured the role of large/old individuals within populations and ecosystems. It is noticeable that for most assessment work, the state of the adult stock is represented by spawning stock biomass (SSB), an indicator which ignores the age/size of individuals within a population (despite the fact that age and size structure are used to calculate SSB). To our knowledge, fisheries management schemes which set objectives for population size/age structure are still exceptional ${ }^{7}$. Whilst limiting the capture of small individuals may be (and has been) achieved by technical adaptations of fishing gears (e.g. mesh size for trawls and nets), no such technique exists for the purpose of keeping large individuals. For this purpose, measures such as regulations of fishing capacity or use of marine protected areas where larger fish would not be subjected to fishing (nor would be small ones) appear to be the most obvious candidates.

\section{Adapting to seasonal and spatial patterns}

Management strategies designed on the basis of the current status of marine populations may

15 consider the spatial structure and dynamics of those populations (e.g. MPAs or seasonal closures). However, climate change (in addition to climate variability) and in particular global warming effects are likely to alter geographical as well as seasonal patterns of many marine populations. One implication is that management strategies which are designed to protect specific individuals or development stages in the current climate situation may be ill-adapted to future situations in which shifts in the space-time distributions of species might occur. An extreme effect of maintaining a spatial/seasonal management scheme under changed climatic conditions would be to trap the population into a life-cycle pattern that is no longer tuned to a modified environment. The example of Alaskan salmon in Bristol Bay suggests that management strategies which are designed to protect the largest unit within a meta-population may not be effective in the medium term (decadal time scale). Within metapopulations, it is often unknown which component may dominate under future climate and management should consider protecting (at least to some level) all components.

\footnotetext{
${ }^{7}$ Some such schemes do exist for small invertebrate stocks such as red sea urchins in the NE Pacific.
} 


\section{Marine protected areas}

The designation of marine protected areas and reserves have been proposed as a management approach to control fishing pressure (e.g. Anonymous, 2001; Anonymous, 2004). Marine protected areas are potentially useful as "hedges" against management errors and an inability to constrain the impacts of fishing on marine populations. They have been proposed for single species management but also as a valid tool towards conservation of species complexes and possibly ecosystems (Lubchenco et al., 2003). Interestingly, Baskett et al. (2005) have suggested that marine protected areas, can protect against strong fisheries-based selection for earlier maturation, therefore limiting the effects of fishing on changes in life history traits of exploited species. Major debates revolve around the necessary size of reserves, their spatial configurations (such as how many, where, how far apart) and their effects on the distribution of fishing effort. Obviously, sizes of reserves will depend on the objectives of management and will need to be appropriate for the life histories of the species involved, for example whether the species are sedentary, have limited mobility and dispersal characteristics, or are migratory. The importance of diverse habitats also needs to be carefully considered as spatial diversity may contribute to increasing buffering capacity against climate variations (Secor, 2007). Much research still needs to be done for the design and implementation of marine protected areas so that these can be useful to fisheries management (Hilborn et al., 2004; Sale et al., 2005). At present, most of the discussions have focussed on understanding the spatial dynamics and connectivity of marine populations in relation to the potential benefits of MPAs (see e.g. Cowen, 2006; Dawnson et al., 2006; Mora et al., 2006; Steneck, 2006), but the interacting effects of climate variability and change also need to be considered. For example, how might the species concerned respond to decadal-scale environmental variability, climate change, and fishing (Pauly et al., 2002; Soto, 2002)? If such aspects are not considered, then marine protected areas, which take a long time to implement, may not function as intended once a climate shift has occurred.

\section{Coping with future responses to climate variability and change}

Fishing effects have and will likely result in populations and ecosystems being more vulnerable to both internal and external forcing (Hsieh et al., 2006; Tittensor et al., in press). The likelihood that responses to climate forcing will be more visible is high. Climate change will likely favour some fractions of the populations that may not be favoured today, so that it is important that diversity (at the individual and population levels) be preserved. 
The differential effects of environmental variation and change on species and life history stages mean that communities are always reassembling. Making predictions about reassembly will be a big challenge on a species by species basis; especially as the existing community governs the fate of incoming species and life history stages and yet the incoming species and life history stages also define the community. There may be some scope to use size-based methods to assess the probability that incoming species and life history stages can enter the community, based on the size-based predation schedule they encounter and the probability of other species and life history stages vacating the niche that they will fill (e.g. Jennings and Brander, this volume, Perry et al., this volume).

\section{Conclusions}

Large amplitude fluctuations in the abundance of marine animal populations have occurred as far as we have been able to measure them (e.g. Baumgartner et al., 1992, Poulsen, this volume) and these fluctuations have in many cases been attributed to climate driven forcing, although they can also result from subtle intra- or inter-specific interaction (e.g. cohort resonance). Whilst overfishing can be dated back to ancient times (Jackson et al., 2001), the present situation is different from past ones in the sense that (1) climate change is adding to climate variability (IPCC, 2001) and (2) overfishing is no longer a regional but an ocean-wide problem (FAO, 2004). Marine species may have evolved to cope with climatic variability over long time scales, but the increase in global fishing pressure has been rapid and is mostly seen from the middle of the $20^{\text {th }}$ century. Some major effects of fishing are (1) reduction in age/size, (2) local depletion leading to removal of metapopulation units, (3) alteration of lifehistory traits, (4) increase in population/ecosystem turnover rates and (5) reduction in ecosystem complexity. All these converge towards a reduction in diversity at the individual, population and ecosystem levels.

25 The complexity of the interactions between marine populations / ecosystems and climate forcing make it unrealistic to separate climate induced from fishing induced effects but calls for studies oriented towards understanding the interactions between climate and fishing. Despite the specificities of local situations, the reduction in marine diversity will likely lead to a reduction in the capacity of populations and ecosystems to adapt and take advantage of climate variability and change. Management objectives must take into account the structure of population and ecosystem in a wider sense as well as the processes at stake in order to maximise the ability of marine fauna to adapt to future climate. 


\section{Acknowledgments}

The authors would like to thank Alec MacCall and an anonymous referee named Andy Bakun for their constructive comments on the first version of the manuscript, Jeremy Lobry, Christian Möllman and Keith Brander for fruitful discussions during the early preparation of

5 this work and the workshop. This work was supported by the international GLOBEC program and EUR-OCEANS, a European Network of Excellence co-funded by the European Commission (6th Framework Programme, contract n511106).

\section{References}

Allain, G., 2004. Modélisation biophysique pour la prévision du recrutement. Couplage stochastique d'un modèle individu-centré de croissance larvaire avec un modèle hydrodynamique 3D pour développer un indice de recrutement de l'anchois dans le golfe de Gascogne. PhD Thesis, Rennes, 183 pp.

Allain, G., Petitgas, P., Grellier, P. and Lazure, P., 2003. The selection process from larval to juvenile stages of anchovy (Engraulis encrasicolus) in the Bay of Biscay investigated by Lagrangian simulations and comparative otolith growth. Fisheries Oceanography, 12(4/5): 407-418.

Anonymous, 2001. Marine protected areas : tools for sustaining ocean ecosystems. National Academy Press, Washington D.C., 272 pp.

Anonymous, 2004. Aquatic protected areas as fisheries management tools. American fisheries society symposium, 42. American Fisheries Society, Bethesda, Maryland, 301 pp.

Balvanera, P. Pfistere, A.B., Buchman, N., He, J.-S., Nakashizuka, T., Raffaelli, D. and Schmid, B., 2006. Quantifying the evidence for biodiversity effects on ecosystem functioning and services. Ecology Letters, 9: 1-11.

Bascompte, J., Melián, C.J. and Sala, E., 2005. Interaction strength combinations and the overfishing of a marine food web. Proceedings of the National Academy of Science USA, 102: 5443-5447.

Baskett, M.L., Levin, S.A., Gaines, S.D. and Dushoff, J., 2005. Marine reserve design and the evolution of size at maturation in harvested fish. Ecological Applications, 15(3): 882-901. 
Baumgartner, T.R., Soutar, A. and Ferreira-Bartrina, V., 1992. Reconstruction of the history of Pacific sardine and Northern anchovy populations over the past two millennia from sediments of the Santa Barbara basin, California. CalCOFI report, 33: $24-40$.

5 Beamish, R.J., McFarlane, G.A. and Benson, A., 2006. Longevity overfishing. Progress in Oceanography, 68(2-4): 289-302.

Begg, G.A., Friedland, K.D. and Pearce, J.B., 1999. The role of life history parameters as indicators of stock structure. Fisheries Research, 43: 141-163.

Berkeley, S.A., Chapman, C. and Sogard, S.M., 2004a. Maternal age as a determinant of larval growth and survival in a marine fish, Sebastes melanops. Ecology, 85(5): 1258-1264.

Berkeley, S.A., Hixon, M.A., Larson, R.J. and Love, M.S., 2004b. Fisheries sustainability via protection of age structure and spatial distribution of fish populations. Fisheries, 29: 23-32.

Beverton, R.J.H. and Lee, A.J., 1965. Hydrographic fluctuations in the North Atlantic Ocean and some biological consequences. In: C.G. Johnson and L.P. Smith (Editors), The Biological Significance of Climate Changes in Britain. Symposia of the Institute of Biology. Academic Press, London, pp. 79-109.

Bianchi, G., Gislason, H., Graham, K., Hill, L., Jin, X., Koranteng, K., ManickchandHeileman, S., Paya, I., Sainsbury, K., Sanchez, F., and Zwanenburg, K. 2000. Impact of fishing on size composition and diversity of demersal fish communities. ICES Journal of Marine Science, 57: 558-571.

Birkeland, C. and Dayton, P.K., 2005. The importance in fishery management of leaving the big ones. Trends in Ecology and Evolution, 20(7): 356-358.

Bjørnstad, O.N., Fromentin, J.-M., Stenseth, N.C. and Gjøsæter, J., 1999. Cycles and trends in cod populations. Proceedings of the National Academy of Science USA, 96: 5066-5071.

Bjørnstad, O.N., Nisbet, R.M. and Fromentin, J.-M., 2004. Trends and cohort resonant effects in age-structured populations. Journal of Animal Ecology, 73: 1157-1167. 
Blanchard, J.L., Dulvy, N.K., Jennings, S., Ellis, J.R., Pinnegar, J.K., Tidd, A. and Kell, L.T., 2005. Do climate and fishing influence size-based indicators of Celtic Sea fish community structure? ICES Journal of Marine Science, 62: 405-411.

Brander, K. and Hurley, P.C.F., 1992. Distribution of early-stage Atlantic cod (Gadus morhua), haddock (Melanogrammus aeglefinus), and witch flounder (Glyptocephalus cynoglossus) eggs on the Scotian Shelf: a reappraisal of evidence on the coupling of cod spawning and plankton production. Canadian Journal of Fisheries and Aquatic Sciences, 49: 238-251.

Brander, K.M., 2005. Cod recruitment is strongly affected by climate when stock biomass is low. ICES Journal of Marine Science, 62: 339-343.

Brodie, W.B., 1987. American plaice in divisions 3LNO - an assessment update. northwest Atlantic Fisheries Organization SCR, Document serial number N1325, 87/40: 51pp.

Brown, C. and Laland, K.N., 2003. Social learning in fishes: a review. Fish and Fisheries, 4: 280-288.

Bundy, A., 2005. Structure and functioning of the eastern Scotian Shelf ecosystem before and after the collapse of groundfish stocks in the early 1990s. Canadian Journal of Fisheries and Aquatic Sciences, 62: 1453-1473.

Cardinale, M. and Arrhenius, F., 2000. The relationship between stock and recruitment: are the assumptions valid? Marine Ecology Progress Series, 196: 305-309.

Chesson, P.L. and Warner, R.R. 1981. Environmental variability promotes coexistence in lottery competitive systems. The American Naturalist, 117(6): 923-943.

Ciannelli, L., Hjermann, D.Ø., Lehodey, P., Ottersen, G., Duffy-Anderson, J.T. and Stenseth, N.C., 2006. Climate forcing, food web structure, and community dynamics in pelagic marine ecosystems. In: A. Belgrano, U.M. Scharler, J. Dunne and R.E. Ulanowicz (Editors), Aquatic Food Webs: an ecosystem approach. Oxford University Press, Oxford, pp. 143-169.

Corten, A., 2002. The role of "conservatism" in herring migrations. Reviews in Fish Biology and Fisheries, 11(4): 339-361. 
Cury, P., Fréon, P., Moloney, C., Shannon, L.J. and Shin, Y.-J., 2005. Processes and patterns of interactions in marine fish populations: an ecosystem perspective. In: A. Robinson and K. Brink (Editors), The SEA: Ideas and Observations on Progress in the study of the Seas. The global coastal ocean: multiscale interdisciplinary processes. Harvard University Press, Cambridge, pp. 475-554.

Cushing, D.H., 1982. Climate and Fisheries. Academic Press, London, 373pp pp.

Cushing, D.H., 1990. Plankton Production and year-class strength in fish populations: an update of the match/mismatch hypothesis. Advances in Marine Biology, 26: 249293.

Cushing, D.H. and Dickson, R.R., 1976. The biological response in the sea to climatic changes. Advances in Marine Biology, 14: 1-122.

Daan, N., Gislason, A., Pope, J.G. and Rice, J.C., 2005. Changes in the North Sea fish community: evidence of indirect effects of fishing? ICES Journal of Marine Science, 62: 177-188.

Dawnson, M.N., Grosberg, R.K. and Botsford, L.W., 2006. Connectivity in marine protected areas. Science, 313: 43-44.

de Roos, A.M., Boukal, D.S. and Persson, L., 2006. Evolutionary regime shifts in age and size at maturation of exploited fish stocks. Proceedings of the Royal Society London B, 273(1596): 1873-1880.

20 Dodson, J.J., 1988. The nature and role of learning in the orientation and migratory behavior of fishes. Environmental biology of fishes. 23(3): 161-182.

Dragesund, O., Johannessen, A. and Ulltang, Ø. 1997. Variations in migration and abundance of the Norwegian spring spawning herring (Clupea harengus). Sarsia, 82: 97-105.

25 Drinkwater, K.F., 2002. A review of the role of climate variability in the decline of northern cod. In: N.A. McGinn (Editor), Fisheries in a changing climate. the American Fisheries Society, Bethesda, Maryland, pp. 113-129.

Drinkwater, K.F., 2006. The regime shift of the 1920s and 1930s in the North Atlantic. Progress in Oceanography, 68: 134-151. 
Dunne, J.A., Williams, R.J. and Martinez, N.D., 2004. Network structure and robustness of marine food webs. Marine Ecology Progress Series, 273: 391-302.

Duplisea, D.E. \& Kerr, S.R. (1995) Application of a biomass size spectrum model to demersal fish data from the Scotian shelf. Journal of Theoretical Biology, 177, 263-269.

Duplisea, D.E., 2005. Running the gauntlet: the predation environment of small fish in the northern Gulf of St Lawrence, Canada. ICES Journal of Marine Science, 62: 412416.

Dutil, J.-D., Castonguay, M., Hammil, M.O., Ouellet, P., Lambert, Y., Chabot, D., Browman, H., Gilbert, D., Fréchet, A., Gagné, J.-A., Gascon, D. and Savard, L., 1998. Environment influences on the productivity of cod stocks: some evidence for the northern Gulf of St. Lawrence and required changes in management practices. Research Document 98/18, DFO. Canadian Stock Assessment Secretariat.

FAO, 2004. The state of world fisheries and aquaculture (SOFIA) 2004, FAO Fisheries Department, Rome.

Faure, V., Inejih, A.C., Demarq, H. and Cury, P., 2000. The importance of retention processes in upwelling areas for recruitment of Octopus vulgaris: the example of the Arguin Bank (Mauritania). Fisheries Oceanography, 9(4): 343-355.

Field, J.C. and Francis, R.C., 2002. Cooperating with the environment: case studies of climate and fisheries in the Northern California current. In: N.A. McGinn (Editor), Fisheries in a changing climate. the American Fisheries Society, Bethesda, Maryland, pp. 245-259.

Fiksen, Ø. and Slotte, A., 2002. Stock-environment recruitment models for Norwegian spring spawning herring (Clupea harengus). Canadian Journal of Fisheries and Aquatic Sciences, 59: 211-217.

Fisher, J.A.D. and Frank, K.T., 2004. Abundance-distribution relationships and conservation of exploited marine fishes. Marine Ecology Progress Series, 279: 201-213. 
Frank, K.T., Drinkwater, K.F. and Page, F.H., 1994. Possible causes of recent trends and fluctuations in Scotian Shelf/Gulf of Maine cod stocks. ICES Marine Science Symposia, 198: 110-120.

Frank, K.T., Petrie, B., Choi, J.S. and Leggett, W.C., 2005. Trophic cascades in a formerly cod-dominated ecosystem. Science, 308: 1621-1623.

Frank, K.T., Petrie, B., Shackell, N.L., and Choi, J.S., 2006. Reconciling differences in trophic control in mid-latitude marine ecosystems. Ecology Letters, 9: 1096:1105.

Fretwell, S. and Lucas, H.L., 1970. On territorial behaviour and other factors influencing habitat distribution in birds. Acta Biotheoretica, 19: 16-36.

Fromentin, J.-M. and Fonteneau, A., 2001. Fishing effects and life history traits: a case study comparing tropical versus temperate tunas. Fisheries Research, 53: 133-150.

Fromentin, J.-M., Stenseth, N.C., Gjøstater, J., Johannessen, T. and Planque, B., 1998. Long-term fluctuations in cod and pollack along the Norwegian Skagerrak coast. Marine Ecology Progress Series, 162: 265-278.

Gislason, S. 2002. The effects of fishing on non-target species and ecosystem structure and function. In Responsible Fisheries in the Marine Ecosystem (eds M. Sinclair \& G. Valdimarsson), CAB International, Walllingford. 255-274.

Gulland, J.A. and Garcia, S.M., 1984. Observed patterns in multispecies fisheries. In: R.M. May (Editor), Exploitation of Marine Communities. Springer, Berlin, pp. 155-190.

Halley, J.M., 1996. Ecology, evolution and 1/f-noise. Trends in Ecology and Evolution, 11(1): 33-37.

Heath, M.R., 2005. Changes in the structure and function of the North Sea fish foodweb, 1973-2000, and the impacts of fishing and climate. ICES Journal of Marine Science, 62: 847-868.

Heyes, C.M. and Galef, B.G., 1996. Social learning in animals: the roots of culture. Academic Press, London.

Hilborn, R., Quinn, T.P., Schindler, D.E. and Rogers, D.E., 2003. Biocomplexity and fisheries sustainability. Proceedings of the National Academy of Science USA, 100(11): 6564-6568. 
Hilborn, R., Stokes, K.J., Maguire, J.-J., Smith, T., Botsford, L.W., Mangel, M., Orensanz, J., Parma, A., Rice, J. and Bell, J., 2004. When can marine reserves improve fisheries management? Ocean \& Coastal Management, 47(3-4): 197-205.

Hjermann, D.Ø., Ottersen, G. and Stenseth, N.C., 2004. Competition among fishermen and fish causes the collapse of Barents Sea capelin. Proceedings of the National Academy of Science USA, 101: 11679-11684.

Hjort, J., 1914. Fluctuations in the great fisheries of Northern Europe viewed in the light of biological research. Rapports et Procès-verbaux des Réunions du Conseil International pour l'Exploration de la Mer, 20: 228pp.

Hjort, J., 1926. Fluctuations in the year classes of important food fishes. Journal du Conseil, 1: 1-38.

Hsieh, C.-h., Reiss, C.S., Hunter, J.R., Beddington, J.R., May, R.M. and Sughihara, G., 2006. Fishing elevates variability in the abundance of exploited species. Nature, 443(7113): 859-862.

Hughes, T.P., 1994. Catastrophes, phase shifts, and large-scale degradation of a Caribbean coral reef. Science, 265: 1547-1551.

Hutchings, J.A., 1996. Spatial and temporal variation in the density of northern cod and a review of hypotheses for the stock's collapse. Canadian Journal of Fisheries and Aquatic Sciences, 53(5): 943-962.

Hutchings, J.A. and Baum, J.K., 2005. Measuring marine fish biodiversity: temporal changes in abundance, life history and demography. Philosophical Transactions of the Royal Society of London Series B, 360: 315-338.

ICES, 1949. Climatic changes in the Arctic in relation to plants and animals. Rapports et Procès-verbaux des Réunions du Conseil International pour l'Exploration de la Mer, 125: 5-52.

ICES, 2006. Report of the working group on the assessment of demersal stocks in the North Sea and Skagerrak (WGNSSK). ICES CM, 2006/ACFM:09: 971pp.

IPCC, 2001: Climate Change 2001: Synthesis Report. A Contribution of Working Groups I, II, and III to the Third Assessment Report of the Integovernmental Panel on Climate Change. Watson, R.T. and the Core Writing Team (eds.). Cambridge University Press, Cambridge, United Kingdom, and New York, NY, USA, 398 pp. 
Jackson, J.B.C., Kirby, M.X., Berger, W.H., Bjorndal, K.A., Botsford, L.W., Bourque, B.J., Bradbury, R.H., Cooke, R., Erlandson, J., Estes, J.A., Hughes, T.P., Kidwell, S., Lange, C.B., Lenihan, H.S., Pandolfi, J.M., Peterson, C.H., Steneck, R.S., Tegner, M.J. and Warner, R.R., 2001. Historical overfishing and the recent collapse of coastal ecosystems. Science, 293: 629-638.

Jennings, S. and Brander, K., this volume. Predicting the effects of climate variation and change on marine communities and the consequences for fisheries. Journal of Marine Systems.

Jennings, S., Greenstreet, S.P. and Reynolds, J.D., 1999. Structural change in an exploited fish community: a consequence of differential fishing effects on species with contrasting life histories. Journal of Animal Ecology, 68: 617-627.

Junquera, S., 1986. Changes in the anchovy fishery of the Bay of Biscay in relation to climatic and oceanographic variations in the North Atlantic. In: T. Wyatt and M.G. Larrañeta (Editors), Long term changes in Marine Fish Populations, Vigo (Spain), pp. 543-554.

Kaitala, V. and Ranta, E., 2001. Is the impact of environmental noise visible in the dynamics of age-structured population? Proceedings of the Royal Society London B, 268: 1769-1774.

Kjesbu, O.S., Kryvi, H., Sundby, S. and Solemdal, P., 1992. Buoyancy variations in eggs of Atlantic cod (Gadus morhua L.) in relation to chorion thickness and egg size: Theory and observations. J. Fish Biol. 41:581-599. Journal of Fish Biology, 41: 581-599.

Kjesbu, O.S., Solemdal, P., Bratland, P. and Fonn, M., 1996. Variation in annual egg production in individual captive Atlantic cod (Gadus morhua). Canadian Journal of Fisheries and Aquatic Sciences, 53: 610-620.

Kritzer, J.P. and Sale, P.F., 2004. Metapopulation ecology in the sea: from Levins' model to marine ecology and fisheries science. Fish and Fisheries, 5(2): 131-140.

Kritzer, J.P. and Sale, P.F., 2006. Marine metapopulations. Academic Press, London, 544 pp. 
Kulka, D.W., 1997. Discarding of cod (Gadus morhua) in the northern cod and northern shrimp directed trawl fisheries, 1980-94. Northwest Atlantic Fisheries Organization Scientific Council Studies, 29: 67-79.

Law, R., 2000. Fishing, selection, and phenotypic evolution. ICES Journal of Marine Science, 57: 659-668.

Law, R. and Grey, D.R., 1989. Evolution of yields from populations with age-specific cropping. Evolutionary Ecology, 3: 343-359.

Law, R. and Rowell, C.A., 1993. Cohort structured populations, selection responses, and exploitation of the North Sea cod. In: K. Stokes, J.M. McGlade and R. Law (Editors), The exploitation of evolving resources. Springer Verlag, Berlin, pp. 155173.

Lawton, J.H., 1988. More time means more variation. Nature, 334: 563.

Link, J.S., 2002. Does food web theory work for marine ecosystems? Marine Ecology Progress Series, 230: 1-9.

Link, J.S., Stockhausen, W.T. and Methratta., E.T., 2006. Food-web theory in marine ecosystems. In: A. Belgrano, U.M. Scharler, J. Dunne and R.E. Ulanowicz (Editors), Aquatic Food Webs: an ecosystem approach. Oxford University Press, Oxford, pp. 98-113.

Longhurst, A., 1998. Cod: perhaps if we all stood back a bit? Fisheries Research, 38: 101108.

Longhurst, A., 2002. Murphy's law revisited: longevity as a factor in recruitment to fish populations. Fisheries Research, 56(2): 125-131.

Lubchenco, J., Palumbi, S.R., Gaines, S.D. and Andelman, S., 2003. Plugging a hole in the ocean: the emerging science of marine reserves. Ecological Applications, 13(Suppl 1): S3-S7.

Lundberg, P., Ranta, E., Ripa, J. and Kaïtala, V., 2000. Population variability in space and time. Trends in Ecology and Evolution, 15: 460-464.

MacCall, A.D., 1990. Dynamic geography of marine fish populations. Books in recruitment fishery oceanography. University of Washington Press, Washington, 153 pp. 
Makhotin, V., Solemdal, P., Korsbrekke, K. and Salthaug, A., 2001. Types and frequency of malformations and mortality in eggs of Arcto-Norwegian cod: a field study. ICES CM, 2001/N:12: 17pp.

Marshall, C.T., Kjesbu, O.S., Yaragina, N.A., Solemdal, P. and Ulltang, Ø. 1998. Is spawner biomass a sensitive measure of the reproductive and recruitment potential of Northeast Arctic cod? Canadian Journal of Fisheries and Aquatic Sciences, 55: 1766-1783.

Marteinsdottir, G., Ruzzante, D.E. and Nielsen, E.E., 2005. History of North Atlantic cod stocks. ICES CM, 2005/AA19: 17pp.

Marteinsdottir, G. and Thorarinsson, K., 1998. Improving the stock-recruitment relationships in Icelandic cod (Gadus morhua) by including age diversity of spawners. Canadian Journal of Fisheries and Aquatic Sciences, 55: 1372-1377.

Mora, C., Andréfouët, S., Costello, M.J., Kranenburg, C., Rollo, A., Veron, J., Gaston, K.J. and Myers, R.A., 2006. Coral reefs and the global network of marine protected areas. Science, 312: 1750-1751.

Morales, J.M., 1999. Viability in a pink environment: why "white noise" models can be dangerous. Ecology Letters, 2: 228-232.

Murawski, S.A., 1993. Climate change and marine fish distributions: forecasting from analogy. Transactions of the American Fisheries Society, 122: 647-658.

20 Murphy, G.I., 1967. Vital statistics of the Pacific sardine (Sardinops caerulea) and the population consequences. Ecology, 48:731-736.

Murphy, G.I., 1968. Patterns in life history and the environment. The American Naturalist, 102: 391-403.

Myers, R.A., 1998. When do environment-recruitment correlations work? Reviews in Fish Biology and Fisheries, 8: 285-305.

Nakashima, B.S., 1996. The relationship between oceanographic conditions in the 1990s and changes in spawning behaviour, growth and early life history of capelin (Mallutus villosus). Northwest Atlantic Fisheries Organization Scientific Council Studies, 24: 55-68. 
O'Brien, C.M., Fox, C.J., Planque, B. and Casey, J., 2000. Climate variability and North Sea cod. Nature, 404: 142.

Olsen, M.O., Heino, M., Lilly, G.R., Morgan, M.J., Brattey, J., Ernande, B. and Dieckmann, U., 2004. Maturation trends indicative of rapid evolution preceded the collapse of northern cod. Nature, 428: 932-935.

Ottersen, G., Hjermann, D.O. and Stenseth, N.C., 2006. Changes in spawning stock structure strengthen the link between climate and recruitment in a heavily fished cod (Gadus morhua) stock. Fisheries Oceanography, 15(3): 230-243.

Ottersen, G., Kim, S., Huse, G., Polovina, J.J. and Stenseth, N.C. this volume. Major routes by which climate signals force marine populations. Journal of Marine Systems.

Ottersen, G., Loeng, H. and Raknes, A., 1994. Influence of temperature variability on recruitment of cod in the Barents Sea. ICES Marine Science Symposium, 198: 471-481.

Pauly, D., Christensen, V., Guénette, S., Pitcher, T., Rashid Sumaila, U., Walters, C.J., Watson, R. and Zeller, D., 2002. Towards sustainability in world fisheries. Nature, 418: 689-695.

Perry, A.L., Low, P.J., Ellis, J.R. and Reynolds, J.D., 2005. Climate change and distribution shifts in marine species. Science, 308: 1912-1915.

20 Perry, R.I., Cury, P., Brander, K.M., Jennings, S., Möllman, C. and Planque, B., this volume. Sensitivity of marine systems to climate change and fishing: concepts, issues and management responses. Journal of Marine Systems.

Petchey, O.L., Gonzales, A. and Wilson, H.B., 1997. Effects on population persistence: the interaction between environmental noise colour, intraspecific competition and space. Proceedings of the Royal Society London B, 264: 1841-1847.

Petitgas, P., Reid, D., Planque, B., Nogueira, E., O’Hea, B. and Cotano, U., 2006. The entrainment hypothesis: an explanantion for the persistence and innovation in spawning migrations and life cycle spatial patterns. ICES CM 2006/B:07, 9pp.

Planque, B. and Frédou, T., 1999. Temperature and the recruitment of Atlantic cod (Gadus morhua). Canadian Journal of Fisheries and Aquatic Sciences, 56(11): 2069-2077. 
Pope, J.G., Rice, J.C., Daan, N., Jennings, S. and Gislason, H., 2006. Modelling an exploited marine fish community with 15 parameters: results from a simple sizebased model. ICES Journal of Marine Science, 63: 1029-1044.

Poulsen, B., submitted. Historical evidence for the variability of fish populations prior to industrialized fishing. Journal of Marine Systems.

Ripa, J. and Lundberg, P., 1996. Noise colour and the risk of population extinctions. Proceedings of the Royal Society London B, 263(1377): 1751-1753.

Rooney, N., McCann, K., Gellner, G. and Moore, J.C., 2006. Structural asymmetry and the stability of diverse food webs. Nature, 442: 265-268.

Sale, P.F., Cowen, R.K., Danilowicz, B.S., Jones, G.P., Kritzer, J.P., Lindeman, K.C., Planes, S., Polunin, N.C., Russ, G.R., Sadovy, Y. J. and Steneck, R.S., 2005. Critical science gaps impede use of no-take fishery reserves. Trends in Ecology and Evolution, 20(2): 74-80.

Schiermeier, Q., 2004. Climate findings let fishermen off the hook. Nature, 428: 4.

Schwartzlose, R,A., Alheit, J., Bakun, A., Baumgartner, T,R., Cloete, R., Crawford, R.J.M., Fletcher, W.J., Green-Ruiz, Y., Hagen, E., Kawasaki, T., Lluch-Belda, D., Lluch-Cota, S.E., MacCall, A.D., Matsuura, Y., Nevarez-Martinez, M.O., Parrish, R.H., Roy, C., Serra, R., Shust, K.V., Ward, M.N., Zuzunaga, J.Z. 1999. Worldwide large-scale fluctuations of sardine and anchovy populations. South African Journal of Marine Science, 21: 289-347.

Schwing, F., Overland, J., Mendelssohn, R. and Bograd, S. this volume. Climate Change, Teleconnection Patterns, and Regional Processes Forcing Marine Populations in the Pacific. Journal of Marine Systems.

Secor, D.H., 2007. The year-class phenomenon and the storage effect in marine fishes. Journal of Sea Research, 57: 91-103.

Shima, J., 2002. Population connectivity. In: A. Bakun and K. Broad (Editors), Climate and fisheries. Interacting paradigms, scales, and policy approaches. International Research Institute for Climate Prediction (IRI), Honolulu, pp. 23-25.

Shin, Y.-J., Rochet, M.-J., Jennings, S., Field, J.G. and Gislason, H., 2005. Using sizebased indicators to evaluate the ecosystem effects of fishing. ICES Journal of Marine Science, 62(3): 384-396. 
Shurin, J.B., Borer, E.T., Seabloom, E.W., Anderson, K., Blanchette, C.A., Broitman, B., Cooper, S.D. and Halpern, B.S., 2002. A cross-ecosystem comparison of the strength of trophic cascades. Ecology Letters, 5: 785-791.

Slotte, A., 1999. Effects of fish length and condition on spawning migration in Norwegian spring spawning herring (Clupea harengus L.). Sarsia, 84: 111-127.

Slotte, A. and Fiksen, Ø. 2000. State-dependent spawning migration in Norwegian springspawning herring. Journal of Fish Biology, 56(1): 138-162.

Soto, C.G., 2002. The potential impacts of global climate change on marine protected areas. Reviews in Fish Biology and Fisheries, 11: 181-195.

Steele, J.H., 1985. A comparison of terrestrial and marine ecological systems. Nature, 313: 355-358.

Steneck, R.S., 2006. Staying connected in a turbulent world. Science, 311: 480-481.

Tereshchenko, V.V., 1996. Seasonal and year-to-year variations of temperature and salinity along the Kola meridian transect. ICES, CM 1996/C:11: 24pp.

Tittensor, D., Worm, B. and Myers, R.A., in press. Macroecological changes in exploited marine systems. In: J.D. Witman and K. Roy (Editors), Marine Macroecology. University of Chicago Press, Chicago.

Toresen, R. and Østvedt, L.J., 2000. Variation in abundance of Norwegian springspawning herring (Clupea harengus, Clupeidae) throughout the 20th century and the influence of climatic fluctuations. Fish and Fisheries, 1: 231-256.

Trites, A.W., Christensen, V. and Pauly, D., 2006. Effects of fisheries on ecosystems: just another top predator? In: I. Boyd, S. Wanless and C.J. Camphuysen (Editors), Top predators in marine ecosystems. Their role in monitoring and management. Cambridge University Press, Cambridge, pp. 11-27.

25 Vallin, L. and Nissling, A., 2000. Maternal effects on egg size and egg buoyancy of Baltic cod, Gadus morhua: Implications for stock structure effects on recruitment. Fisheries Research, 49(1): 21-37.

Vasseur, D.A. and Yodzis, P., 2004. The color of environmental noise. Ecology, 85(4): 1146-1152. 
Vilhjálmsson, H., 1997. Climatic variations and some examples of their effects on the marine ecology of Icelandic and Greenland waters, in particular during the present century. Rit Fiskideildar, 40: 7-29.

Ward, P. and Myers, R.A., 2005. Shifts in open-ocean fish communities coinciding with the commencement of commercial fishing. Ecology, 86: 835-847.

Warner, R.R., 1988. Traditionality of mating-site preferences in coral reef fish. Nature, 335: 719-721.

Watters, G.M., Olson, R.J., Francis, R.C., Fiedler, P.C., Polovina, J.J., Reilly, S.B., Aydin, K.Y., Boggs, C.H., Essington, T.E., Walters, C.J. and Kitchell, J.F., 2003. Physical forcing and dynamics of the pelagic ecosystem in the eastern tropical Pacific: simulations with ENSO-scale and global-warming climate drivers. Canadian Journal of Fisheries and Aquatic Sciences, 60: 1161-1175.

Worm, B., Barbier, E.B., Beaumont, N., Duffy, J.E., Folke, C., Halpern, B.S., Jackson, J.B.C., Lotze, H.K., Micheli, F., Palumbi, S.R., Sala, E., Selkoe, K.A., Stachowicz, J.J. and Watson, R., 2006. Impacts of biodiversity loss on ocean ecosystem services. Science, 314(5800): 787-790.

Worm, B. and Myers, R.A., 2004. Managing fisheries in a changing climate. Nature, 429: 15. 


\section{Figure legends}

Fig 1. Maximum length attained by fish species landed from 1950 to 2000 in the North Atlantic (continuous line) and for the global coastal ocean (dotted line). Modified after Trites et al. (2005).

Fig 2. Top: Age-composition of the biomass in the Arcto-norwegian cod spawning stock in percent per age group for (a) 1946-55 and (b) 1993-2002. Bottom: Moving, 21-yr time window, correlations between cod year-class strength at age 3 and the temperature measured at the Kola meridian in December-March over 0-200 m depth (data 1943-99). Modified after Ottersen et al. (2006).

Fig 3. Top: map of Bristol Bay, Alaska, showing the major lake systems producing sockeye salmon. Middle : long-term variability in the climate of the Pacific expressed by the North Pacific Decadal Oscillation Index (PDOI) ; the vertical dashed line indicate the start of the recent period of positive PDOI. Bottom: catch history of the three major fishing areas within Bristol Bay (bottom). Modified after Hilborn et al. (2003).

Fig 4. A schematic representation of the possible combined effects of fishing and climate decadal oscillations on fish populations with multiple sub-units. The population is composed of three sub-units $A, B$ and $C$. Subunit $A$ is favoured under climate situation 1 (left) and unfavoured under climate situation 2 (right). The reverse is true for subunit $B$ and subunit $C$ is unaffected. Transition from climate situation 1 to 2 induces changes in the respective contributions of $A$ and $B$ to the productivity of the whole population. Time-lagged reaction of exploitation level leads to overexploitation of subunit $A$ (and underexploitation of subunit $B$ ), which can ultimately result in the collapse of subunit $A$. The increase in productivity of subunit $B$ is gradually matched by an increase of fishing pressure on this subunit. The return to climate situation 1 provokes a decline in the productivity of subunit $B$ which is not compensated by subunit $A$ which has collapsed (and may be in a recovery phase). Maintenance of high fishing pressure on subunit $B$ can ultimately lead to collapse, leaving the population with only subunit $C$ which displays low productivity.

Fig 5. A schematic overview of historic changes in the adult Norwegian Spring Spawning herring migration routes, feeding and wintering areas during the latter half of the twentieth century. The plots show (a) the normal migration pattern during the warm period before 1965, 
(b and c) the pattern following the Great Salinity Anomaly until the stock collapsed in 1968, (d) during years of low stock abundance, and (e) the migration pattern in the mid-1990s. Modified after Vilhjálmsson (1997).

Fig 6. Schematic food webs of the tropical Pacific (top) and Barents Sea (bottom). Arrows indicate the direction of energy flow from prey to predator. DOM: dissolved organic material. Modified after Ciannelli et al. (2006). 


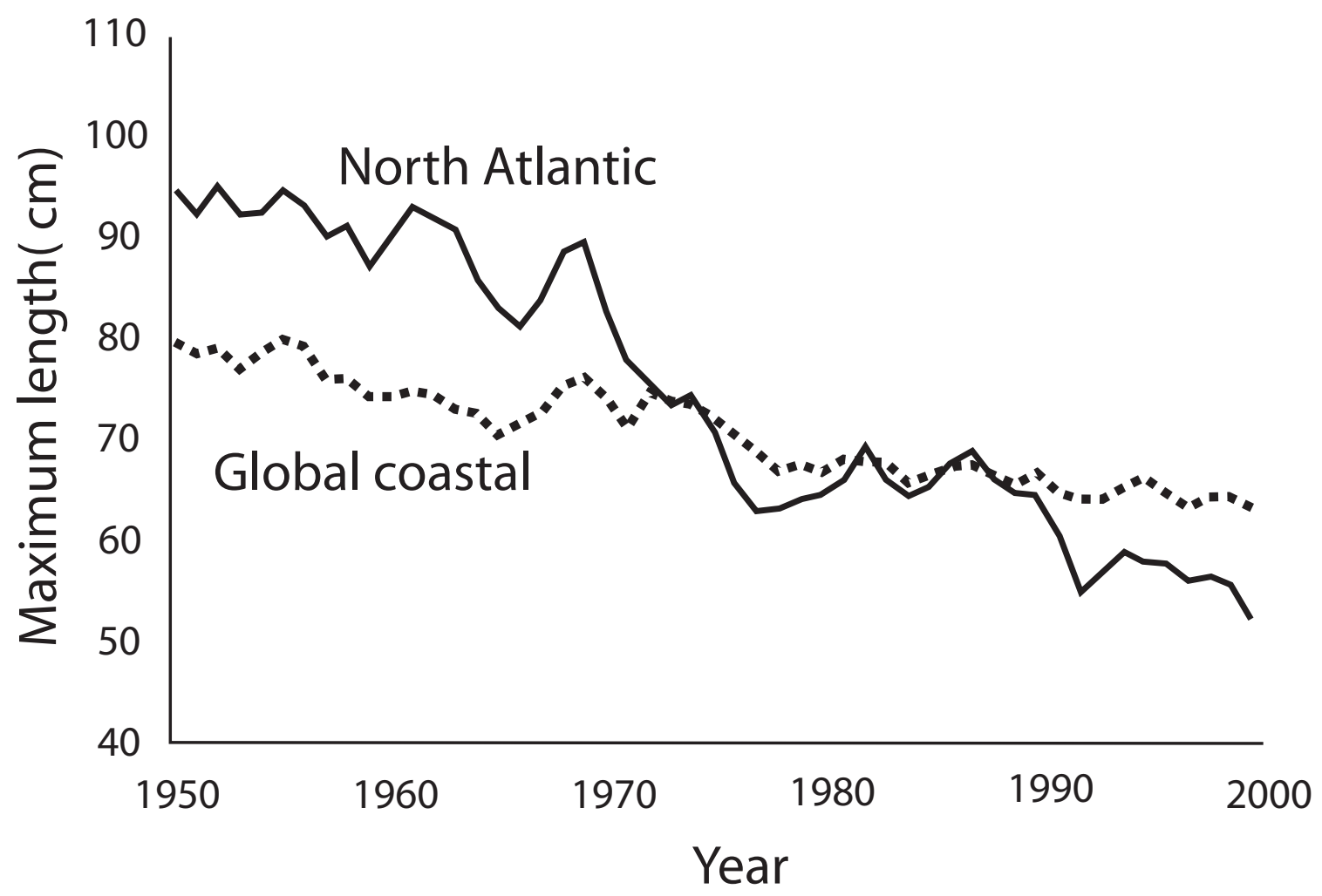

Figure 1. Planque et al. 
a) 1946-1955

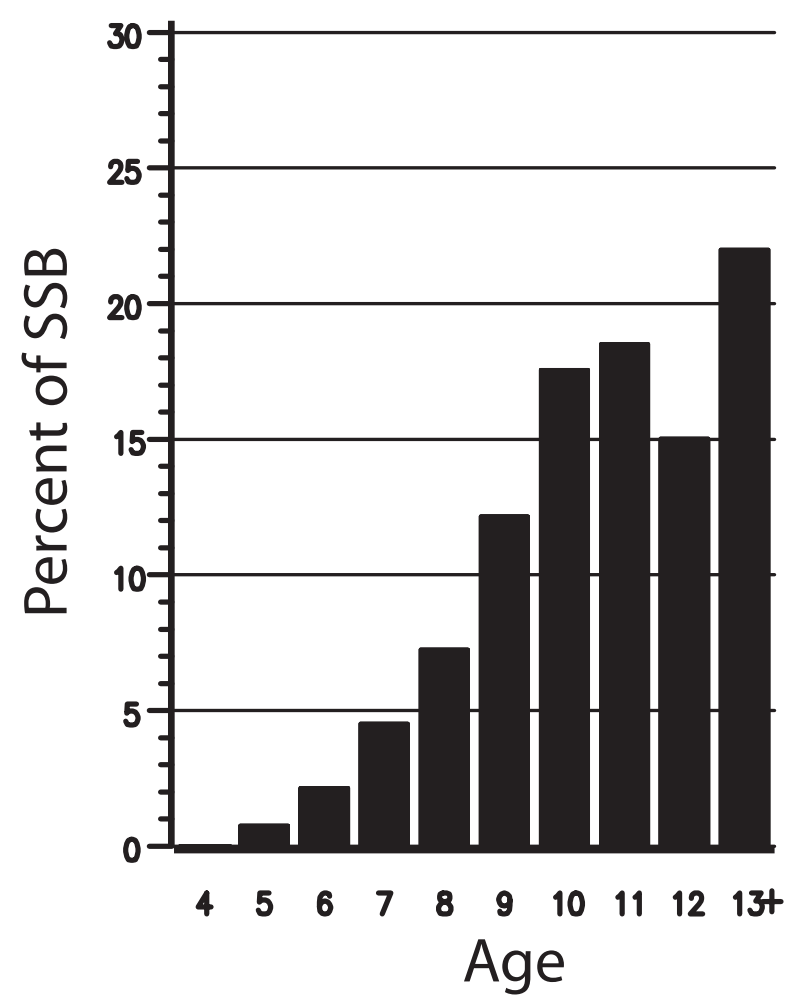

b) $1993-2002$

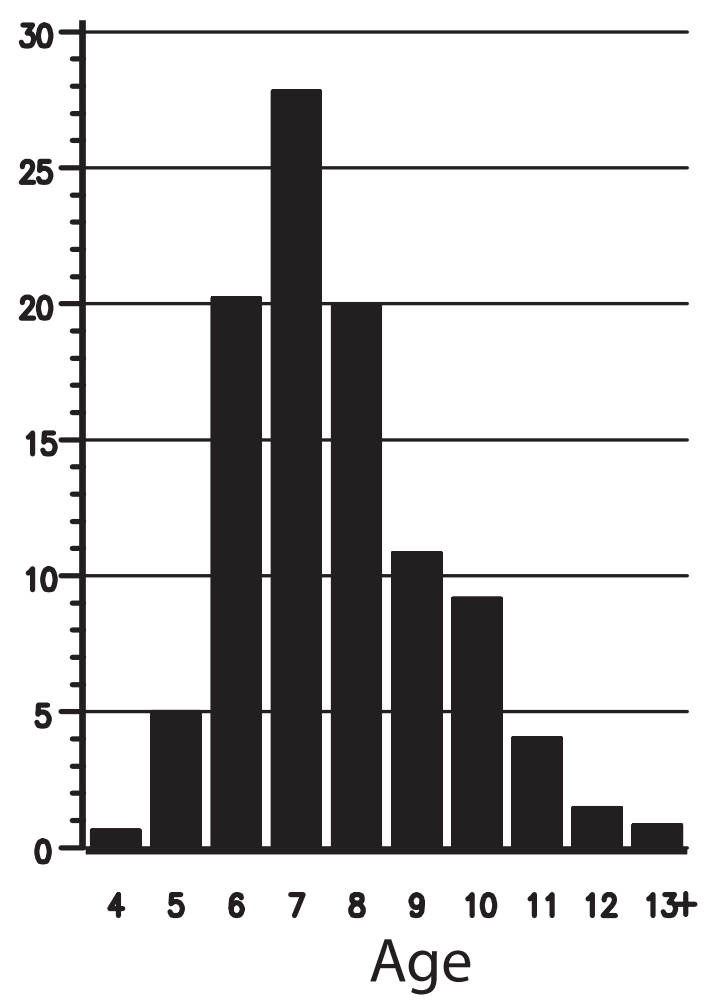

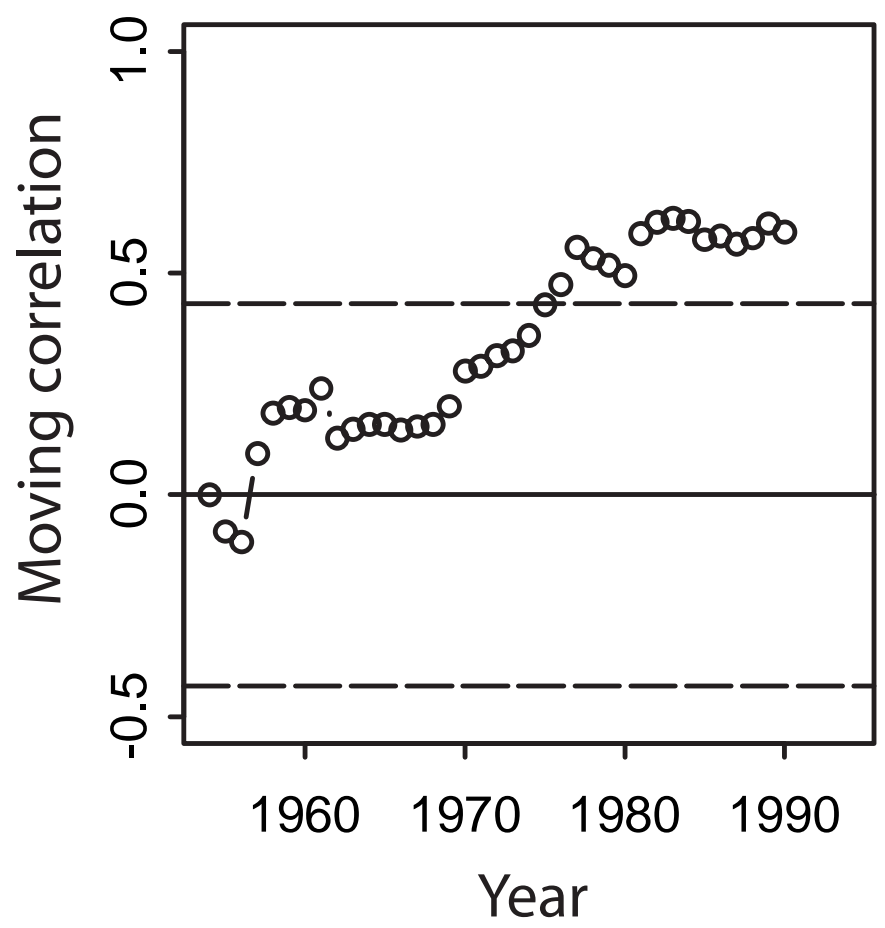

Figure 2. Planque et al. 

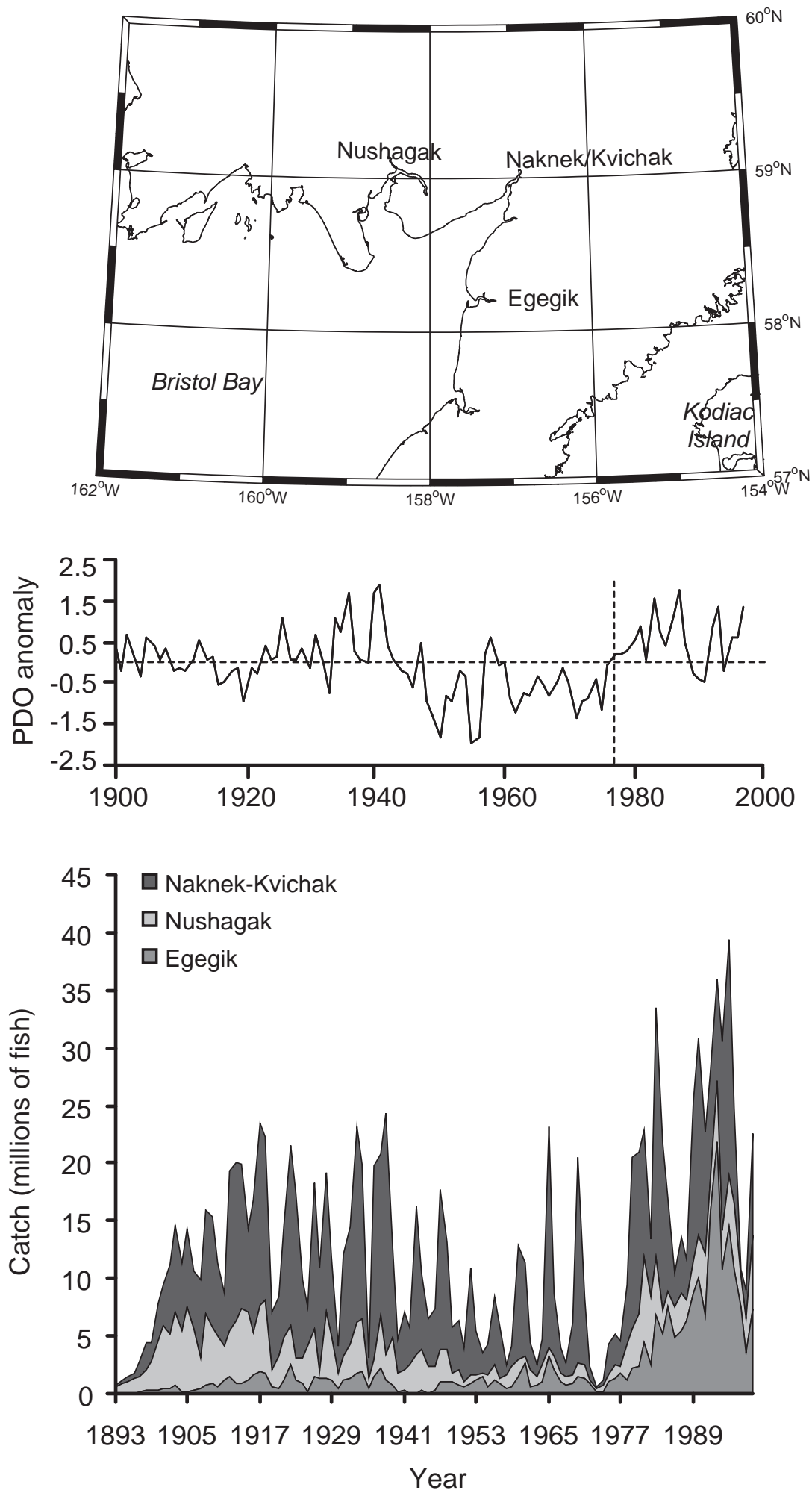

Figure 3. Planque et al. 
Climate Situation 1

Climate Situation 2

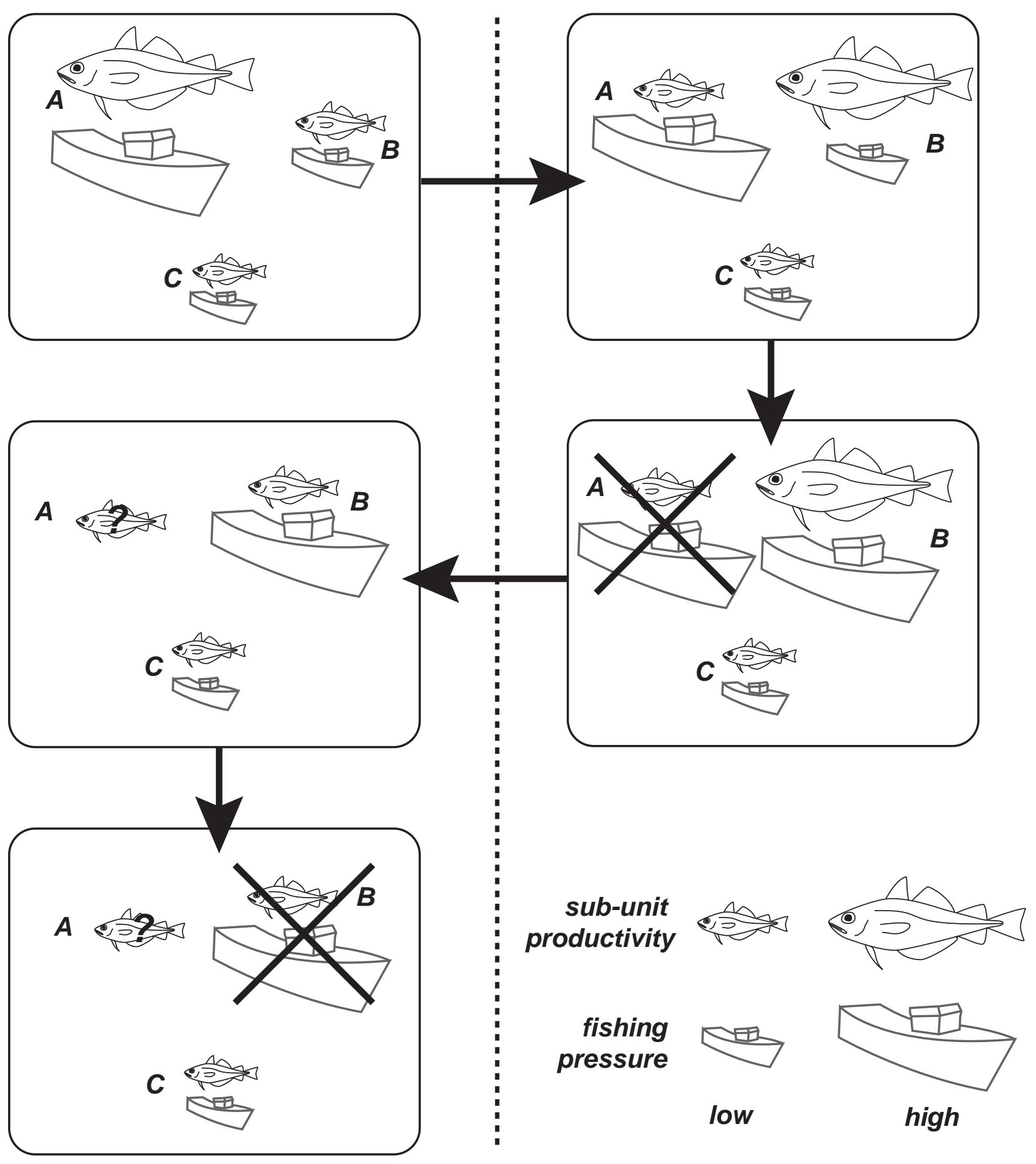

Figure 4. Planque et al. 

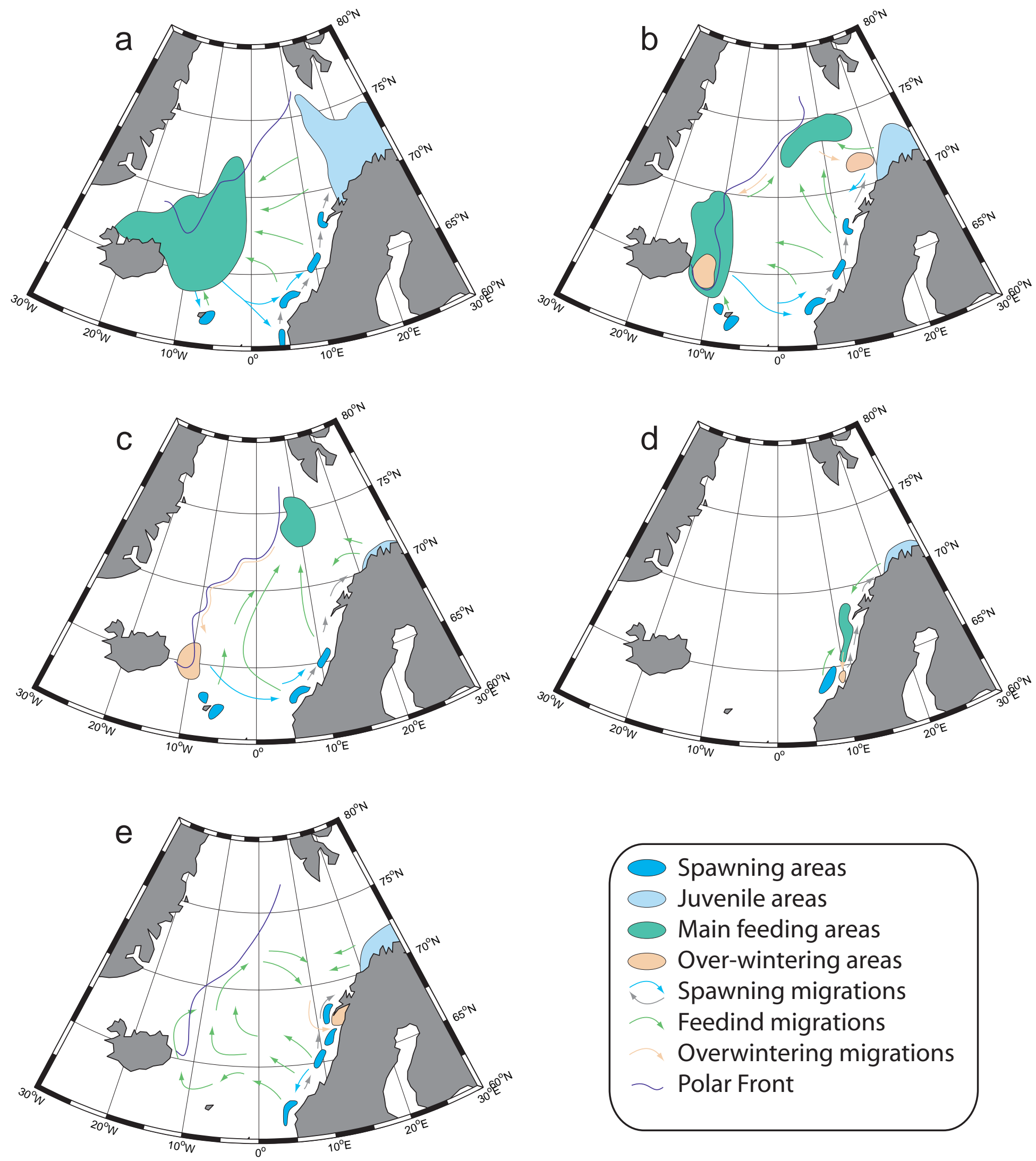

\section{Spawning areas}

Juvenile areas

Main feeding areas

Over-wintering areas

Spawning migrations

Feedind migrations

Overwintering migrations

Polar Front

Figure 5. Planque et al. 


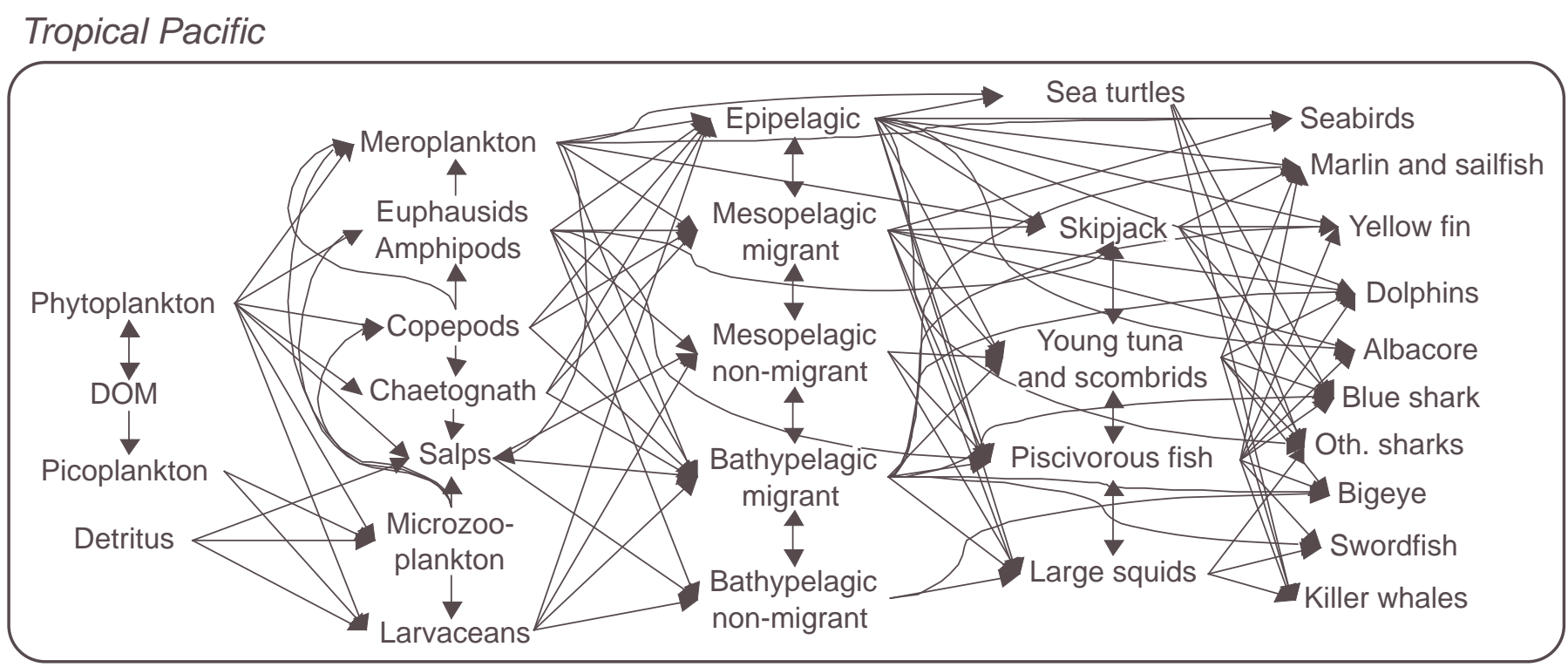

\section{Barents Sea}

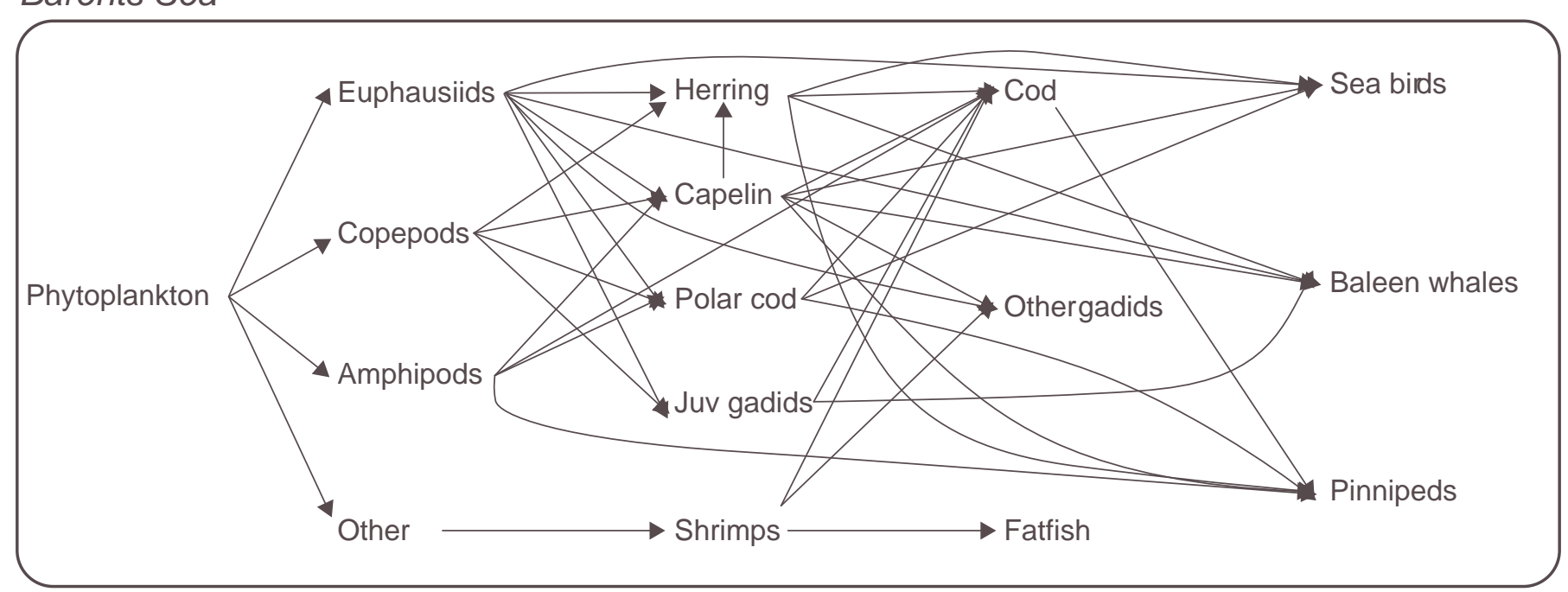

